Portland State University

PDXScholar

\title{
A Comparison of Linguistic Features in the Academic Writing of Advanced English Language Learner and English First Language University Students
}

Margo K. Russell

Portland State University

Follow this and additional works at: https://pdxscholar.library.pdx.edu/open_access_etds

Part of the Applied Linguistics Commons, First and Second Language Acquisition Commons, and the Rhetoric and Composition Commons

Let us know how access to this document benefits you.

\section{Recommended Citation}

Russell, Margo K., "A Comparison of Linguistic Features in the Academic Writing of Advanced English Language Learner and English First Language University Students" (2014). Dissertations and Theses. Paper 2023.

https://doi.org/10.15760/etd.2022

This Thesis is brought to you for free and open access. It has been accepted for inclusion in Dissertations and Theses by an authorized administrator of PDXScholar. Please contact us if we can make this document more accessible: pdxscholar@pdx.edu. 
A Comparison of Linguistic Features in the Academic Writing of Advanced English Language Learner and English First Language University Students

by

Margo K. Russell

A thesis submitted in partial fulfillment of the requirements for the degree of

\author{
Master of Arts \\ in \\ Teaching English to Speakers of Other Languages
}

Thesis Committee:

Susan Conrad, Chair

Lynn Santelmann

Linnea Spitzer

Portland State University

2014 


\begin{abstract}
Writing for an academic purpose is not an easy skill to master, whether for a native English speaker (L1) or an English language learner (ELL). In order to better prepare ELL students for success in mainstream content courses at the university level, more must be known about the characteristics of student writing in the local context of an intensive English program. This information can be used to inform ELL writing instructors of which linguistic features to target so that their students produce writing that sounds appropriate for the academic written register.
\end{abstract}

Two corpora of 30 research essays each were compiled, one of L1 student writing done in various departments at Portland State University, and the other of ELL writing produced in an advanced writing course in Portland State University's Intensive English Language Program. The corpora were compared for the frequencies of 13 linguistic features which had been previously found in significantly different frequencies in L1 and ELL essays (Hinkel, 2002).

The tokens of each feature in each essay were counted, and the frequency rate was calculated in each case. The results of the Mann-Whitney U test found 6 features with significantly different frequency rates between the two corpora. The following features were more frequent in L1 essays than in ELL essays: modal would, perfect aspect, passive voice, reduced adjective clause, and it-cleft. In addition, the type/token ratio was found be significantly higher in L1 essays than in ELL essays. 
An analysis of how each of the significant features was used in the context of ELL and L1 essays revealed the following: Both student groups were still acquiring the appropriate use of modal would; the majority of students in both groups did not utilize itclefts; the lower type/token ratio in ELL essays meant that these students used a more limited vocabulary than did L1 students; and ELL students were still acquiring the accurate and appropriate uses of perfect aspect, passive voice, and reduced adjective clauses, whereas L1 students used these features grammatically and for the standard uses.

To apply these findings to the ELL writing classroom, instructors should help students raise their awareness of these six features in their own academic writing by leading students in identifying grammatical and ungrammatical uses of these features and providing practice in differentiating between uses which are standard to the register of academic writing and uses which are appropriate only in conversation. Two sample activities are included to illustrate how to implement these recommendations. 


\section{Dedication}

To my biggest supporters, Jack and Annette Russell, for shaping the person I've become with their unconditional love.

In loving memory of Kevin Allen Gibler (1984-2014)

A true friend and gentle spirit whose presence in my life has made all the difference. 


\section{Acknowledgments}

In acknowledging those who have influenced and aided me throughout the process of writing a master's thesis, there are simply too many to name to whom I owe my gratitude. Above all, I thank my parents, John and Annette Russell, for their understanding and patience as I stressed through each deadline, and for their life-long encouragement of me to pursue happiness, whatever that may look like. In that vein, I also thank Sara Marruffo, who has sacrificed more than anyone should have for me to return to school, and whose years of good advice, thought-provoking conversation, and stalwart support have helped me get to where I am today.

I could never have attempted anything like writing a thesis without the guidance of my gracious advisor, Susan Conrad; her encouragement, insight and enthusiasm for this project kept me in perpetual motion toward my goal. I thank her for investing her time in me and for believing in my potential. Thanks to my committee, Susan, Lynn Santelmann and Linnea Spitzer, for generously sharing their time and collective wisdom with me. It is also important that I thank Monika Mulder at the IELP Learning Center, who has been a valued mentor to me, and all of my professors at PSU, who have expanded my mind in ways I didn't know possible.

Finally, my personal gratitude goes to my friends/classmates/colleagues in the MA TESOL program, who are always willing to lend an ear/ commiserate, share their advice and unique perspectives with me, and who have made this "two-year" pursuit of education and enlightenment the most rewarding and enriching experience of my life. 
Table of Contents

Abstract

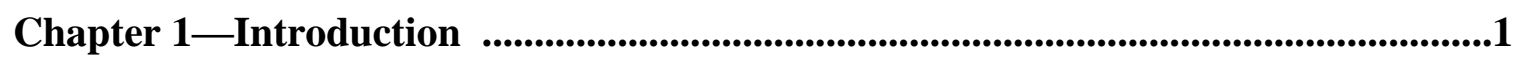

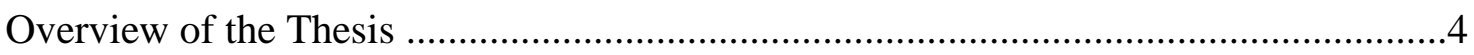

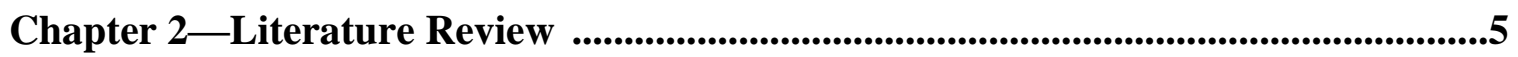

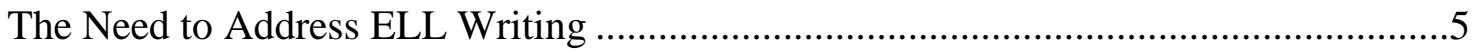

Distinguishing between Genre and Register ................................................... 10

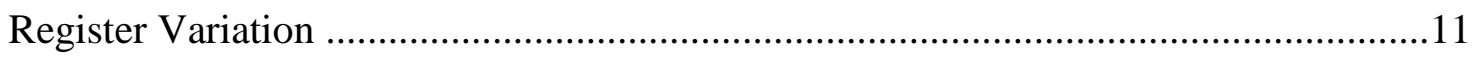

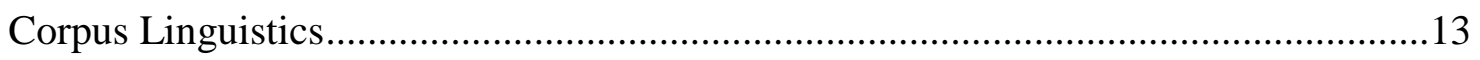

Studies of Second Language Writing ............................................................. 15

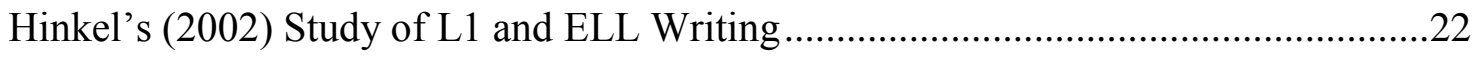

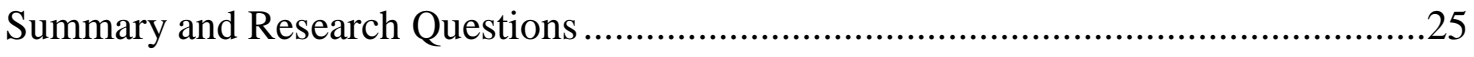

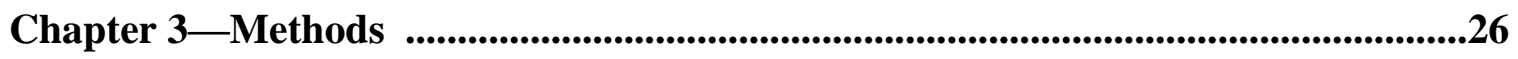

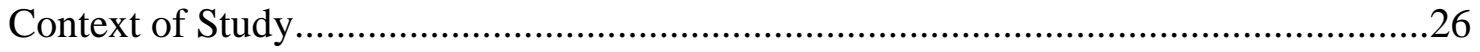

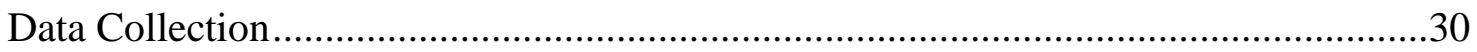

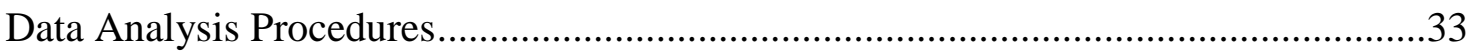

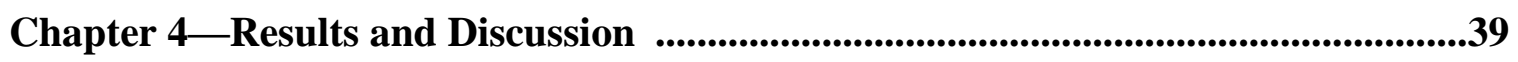

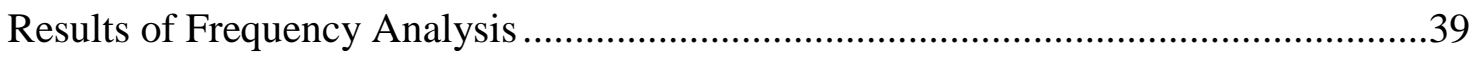

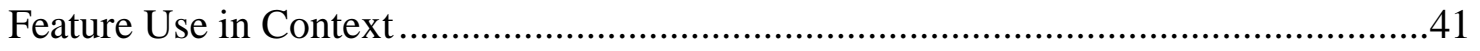

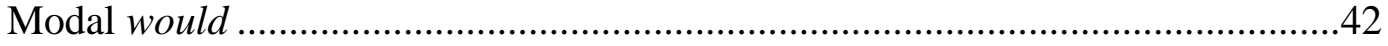

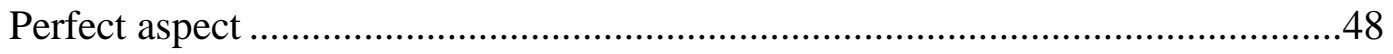

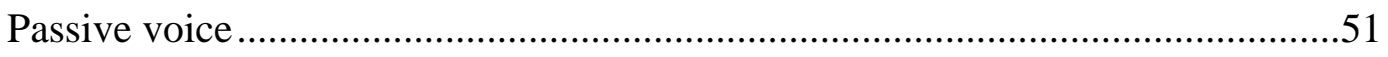




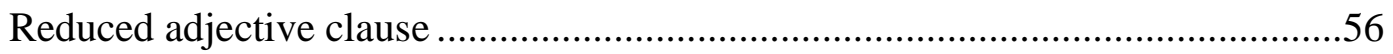

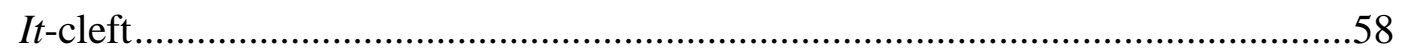

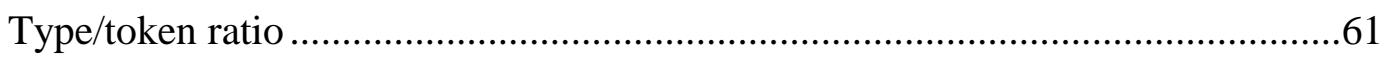

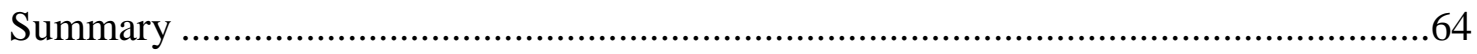

Chapter 5-Conclusion ....................................................................................................................66

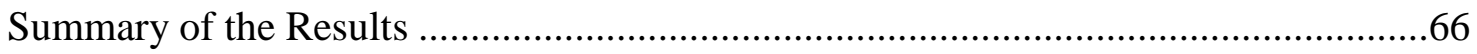

Applications for Language Teaching ............................................................ 71

Limitations and Suggestions for Future Research ...............................................79

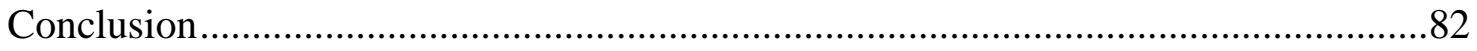

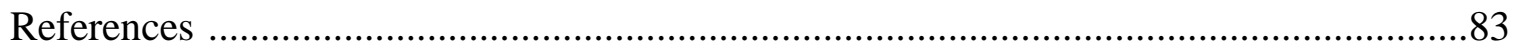




\section{List of Tables}

Table 2.1: Examples of linguistic features and findings of prior research regarding frequency of features in student writing

Table 2.2: Features of text found in significantly different frequencies between samples of L1 and ELL writing (Hinkel, 2002).

Table 3.1: Average words per sample and total word in the L1 and ELL corpora............31

Table 3.2: Number of samples from each department and course level in L1 corpus.......31

Table 3.3: Examples of essay topics and disciplines represented in ELL corpus..............33

Table 3.4: Features analyzed for frequency rate in the present study............................34

Table 4.1: Test statistics for features with significantly different frequency rates ...........40

Table 4.2: Test statistics for features that did not have significantly different frequency rates

Table 4.3: Median frequency rates per 1000 words (except type/toke ratio) and ranges for all features

Table 4.4: Percentage of use and examples of would by meaning

Table 4.5: L1 non-standard use of would and revised sentences .46

Table 4.6: Violation of information structure in ELL student writing .53

Table 4.7: Examples of ineffective choices of voice and revised sentences

Table 4.8: Examples of full and reduced adjective clauses with -ed and -ing participle clauses

Table 4.9: ELL use of full adjective clauses and revised sentences with reduced adjective clauses

Table 4.10: Verbs used in reduced adjective clauses with the highest percentage of difference in frequencies between ELL and L1 corpora.

Table 4.11: Examples of ELL essays with unnecessary use of reduced adjective clause with verb call and revised sentences 
Table 4.12: Example from ELL writing where use of $i t$-cleft would strengthen emphasis and contrast and revised passage

Table 4.13: Number of tokens of three open-class words and their percentage of total words in two essays about reverse culture shock....................................................62 


\section{List of Figures}

Figure 5.1: Sample materials: Contrasting uses of modal would in conversation and academic writing

Figure 5.2: Sample materials: Correcting uncommon uses of would in academic writing 


\section{Chapter 1- Introduction}

The purpose of this study is to better understand the writing needs of advanced level English language learners (ELLs) who are preparing to enter degree-granting programs at U.S. universities. Specifically, the research compares the frequencies of linguistic features in the writing of students in main-stream university courses who speak English as their first language (L1) with those of ELL students in an advanced level ELL writing course. The results of the analysis inform decisions about which features to target for pedagogical intervention in ELL writing instruction. In particular, the results further the goal of English for Academic Purposes (EAP) to understand the difficulties specific to ELL students learning academic writing, and inform EAP instructors at Portland State University of any gaps that exist between the writing of ELL students and that of their future L1 classmates.

Writing is a crucial skill; in higher education, so much of academic success is dependent upon the ability to clearly communicate one's ideas through writing. Beyond the university, strong writing skills are sought after in the job market regardless of the profession. However, English language learners face many challenges when learning to write in a second language beyond mastering grammatical structures and amassing a broad vocabulary. ELLs must learn to distinguish between academic and conversational English with regards to the conventional words, phrases, and sentence structures (register knowledge; Biber and Conrad, 2009, Chapelle, 1998, Gardner, 2012). They must also learn the requirements for writing in a variety of genres, including the appropriate information to include and in which order to include it (genre knowledge; Swales, 1990; 
Biber and Conrad, 2009; Martin \& Rose, 2008). Finally, they must understand the differences between writing for the academy (skills taught in general EAP courses), and writing for their specific careers (Gilquin, 2007).

As an aspiring teacher of writing for EAP, I am interested in learning more about how to prepare students for the type of writing assignments they will be expected to do for content courses in their degree programs. Through my experience as a graduate student in the field of Teaching English to Speakers of Other Languages (TESOL), I have learned about the challenges that ELL students face in English-medium content courses. For instance, I learned of a Portland State professor of a 100 level course who approached an EAP instructor to complain that the ELL students were such poor writers compared to the L1 students that he had difficulty reading their assignments. His claim made me wonder whether L1 and ELL writing is in fact different, and if so, in what ways? To begin to answer this, I decided to conduct a quantitative analysis comparing linguistic features found by prior studies to occur in differing frequencies between these two student groups.

I chose a corpus-based approach for my research because this approach allows for the analysis of more linguistic features by more writers than other approaches (Biber, Conrad, and Reppen, 1998). As I describe in Chapter 2, corpus linguistics provides empirical evidence for how language is actually used in context, instead of how teachers or linguists think it is used (Granger, 1998, Biber \& Reppen, 1998, Breyer, 2011). In comparison to the findings of earlier approaches, corpus-based studies have provided a more accurate, descriptive knowledge of English, which has led to the creation of new 
materials for enhancing ELL instruction (Reppen, 2012; Chang \& Kuo, 2011). Previous analyses of learner corpora have proven useful for determining the ways that ELL writing differs from the standard academic register (e.g., Gilquin, Granger, \& Paquot, 2007) and from the writing of L1 students (e.g., Hinkel, 2002). Past corpus-based research of learner writing has shown that although there is overlap in the sort of inconsistencies that appear in ELL and L1 student writing compared to texts written in the standard academic register (Beck, 2007), writing of ELL students contains distinct differences with regards to the frequency of certain linguistic features in comparison to novice L1 writing (Gilquin, et al., 2007; Hinkel 2002). One particular way that ELL student writing differs from L1 student writing is that ELL writing has been found to share more features of the spoken register of English (Hinkel, 2002; 2003a). Due to differences like this, Gilquin, et al. (2007) called for more empirical research that utilizes learner corpora in order to better understand the needs of ELL students and to develop teaching materials that target specific problems. The present study seeks to better understand the characteristics of ELL writing in order to inform EAP instructors of the challenges that most need to be addressed in writing courses and to inform the development of pedagogical interventions for helping students improve their writing.

My study follows from research done by Hinkel (2002), which compared the frequencies of 68 linguistic features in a corpus of 1457 essays written by L1 and ELL students in U.S. universities. I employed Hinkel's method of data analysis but targeted a more specific set of data: 30 essays each from ELL and L1 students at Portland State University were analyzed for 12 features found in Hinkel's study to be used in 
significantly different frequencies between L1 and ELL writing samples. An additional feature for counting the diversity of words in a text, type/ token ratio, was analyzed to compare the breadth of vocabulary used by each group of students. I counted the tokens of each feature in each essay and performed a statistical analysis to find significant differences in the frequencies of each feature between the two groups of essays. After discovering which features were significantly different in frequency, I analyzed the function(s) of each of these features by comparing examples in the ELL and L1 essays.

\section{Overview of the Thesis}

Before describing the present study in detail, I provide the background necessary for understanding the research questions. Chapter 2 introduces literature about the challenges that ELL students face in learning to write academic English, the importance of register as a variable in text analysis, and how corpus linguistics is used to study second language writing. It then continues with a review of prior research analyzing the differences in use of linguistics features between L1 writing and ELL writing. Chapter 3 describes the context for the present study and the methods I employed to carry out the analysis of the selected linguistic features. Chapter 4 presents the results of the frequency analysis and discusses the findings through an analysis of each feature's use in the context of the essays. Drawing on the results of this study, Chapter 5 provides suggestions for the explicit teaching of the significant linguistic features in EAP writing courses. The chapter concludes with a discussion of the study's limitations and suggestions for future research. 


\section{Chapter 2- Literature Review}

Teachers and researchers have noted that English language learners face many challenges with the kinds of writing required in college coursework, yet writing is a necessary skill for achieving success in college and in a career. A fundamental part of learning to write for academic purposes is becoming familiar with the genres and registers of academic English, knowledge which is developed over the course of a fouryear degree program. Understanding the extent to which ELL students employ the linguistic features of academic registers in their writing is a first step in closing any gaps in ability that may exist between ELL students and their English L1 classmates in university courses. The literature review begins with a discussion of the need to address ELL academic writing and provides information about ELL students in U.S. universities. The sections that follow provide an overview of register variation, corpus linguistics, and past research analyzing the differences in the use of words and structures between ELL and L1 student writing. After that, I discuss the findings of Hinkel (2002), which used a corpus of student writing to compare the frequencies of linguistic features in L1 and ELL writing samples. Finally, I present the research questions addressed in the present study.

\section{The Need to Address ELL Writing}

Historically, large numbers of international students have chosen to study in the U.S. due to a lack of educational options in their home countries, the status that a U.S. education carries abroad, and the high quality of education that opens doors for career opportunities in their home countries, the U.S., or a third country (Terzian \& Osborne, 2006). Since the 1950's there has been a steady and, at times, exponential increase in the 
number of students in U.S. institutions of higher learning who speak English as a second or additional language. In the 2012-2013 school year, a record number of 819,644 international students studied in U.S. colleges and universities, making up $3.9 \%$ of all students enrolled in U.S. institutions of higher education. This represents a $40 \%$ increase since 2002-2003, only a decade earlier (Institute of International Education [IIE], 2013). The number of students enrolled in ESL programs in U.S. universities also continues to grow, with 29,603 students in 2010-2011; this was a $24 \%$ increase from the year before (Smith-Barrow, 2013). At Portland State University, where the present study was conducted, $10 \%$ of 2010 graduates had participated in English as a second language classes. This represents the university with the largest number of English language learners in the country for that year (Hopkins, 2011).

The need to address ELL writing stems from the expectations of U.S. institutions that all students demonstrate a high level of written communication skills by the time they graduate, whether English is their first or second language. To ensure that ELL students achieve this level of proficiency, they are placed either in English language courses to learn the conventions and expectations of university-level discourse, or having already attained a certain level of language ability, in English composition or general studies courses enrolling both L1 and ELL students. The approaches of English department faculty and English as a second language faculty usually differ in how they offer writing instruction. Often the focus of the former is writing for the humanities and has a more ideological approach, whereas the latter more commonly focuses on English for Academic Purposes (EAP) and takes a more pragmatic approach (Santos, 1992; 
Benesch, 1993). Because mainstream composition courses are usually offered within English departments, the approach to writing instruction often emphasizes personal voice in writing, as well as the social and political implications of the written word (Santos, 1992). In contrast, second language writing is considered a subfield of applied linguistics, is more product-oriented and values the field's "prevailing standards of inquiry and research" (Santos, 1992, p. 164). The courses tend to focus on the standard expectations for different types of writing (e.g. expository writing or research papers) and emphasize the requirements of an assignment over its wider social and political implications. In any case, ELL students will receive some form of general writing instruction before entering into courses for their major, where academic writing skills will be essential.

Once enrolled in a degree program, ELL students are generally held to the L1 standard of written discourse whether or not they plan to publish research or pursue a writing-intensive career. This expectation has been criticized by those in the field of critical applied linguistics for heralding "native-like" language abilities as a one-size-fitsall standard for ELLs to emulate, while not taking into account the identity, life circumstances, or personal goals of the individual (Ramanathan \& Atkinson, 1999; Benesch, 1993). On the other hand, the dominant argument in favor of English for Academic Purposes (EAP) is that while "native-like" abilities are not the end goal, ELL students still must achieve a level of proficiency in writing that will allow them to participate in academic discourse and assert themselves as competent professionals in their field (Santos, 2001; for a discussion of this issue, see Benesch, 2001, Chapter 3 and Casanave, 2004, Chapter 6). A further argument of EAP contends that students of English 
as a second or foreign language expect their instructors to teach them the standard language and conventional organization for college-level writing, with the understanding that this base knowledge of academic English is vital for their future studies and future professions. The current study assumes the point of view of EAP, in which the writing instructor is responsible for providing a foundation upon which ELL students may build the language and communication skills needed for the writing tasks that they will do in mainstream university courses.

As mentioned previously, an important aspect of becoming proficient in academic English is learning to write appropriate academic language and becoming familiar with the genres of academic and professional life. Both L1 and ELL students build this knowledge of academic discourse through reading the work of authorities in the field and through the practice of writing the sub-varieties of academic English, such as the persuasive essay and the lab report. While teaching students about the sections required in a lab report is rather straightforward, teaching which words are most effective for expressing the ideas within the lab report is much more challenging since even teachers of English language are often unaware of the choices they make regarding the words and grammatical structures in their own writing. My experience has been that EAP teachers may unwittingly expect that if ELL students work hard enough in their various EAP courses, their writing will eventually begin to take on the characteristics of the academic language, but in fact, students could greatly benefit from receiving explicit instruction in this area prior to entering content courses. 
In fact, research implementing the genre-based approach to instruct ELL students in academic writing has found that after explicit instruction of genre and register (organization of ideas and linguistic features, which will be explained in the next paragraph) students were better able to produce essays that followed the conventions of academic writing (Kongpetch, 2006; Cheng, 2008; Chen \& Su, 2012; Yasuda, 2011; Yayli, 2011). For example, Kongpetch (2006) used this approach to introduce Thai university students to persuasive essay writing. The instruction consisted of four steps: building students' content knowledge, modelling the organization and linguistic features used in the persuasive essay and the rhetorical moves within and between each paragraph, co-constructing persuasive essays in small groups, and finally, independently writing persuasive essays, with students putting into practice what they had learned in the first three steps. The final product, students' own persuasive essays, provided evidence that students were able to follow explicit instruction to successfully produce writing that contained the appropriate organization of ideas and linguistic features that reflect the academic written register.

Up to this point in the literature review, I have used the terms genre and register without examining the differences between the two. Since previous studies have sometimes used genre and register interchangeably, and some researchers have changed their operational meanings over time (Biber \& Conrad, 2009), it is worth clarifying the difference between them before explaining the importance of register to my study. 


\section{Distinguishing between Genre and Register}

The terms genre and register both apply to analyzing characteristics of varieties of texts, but when the terms are clearly distinguished and defined, they are typically differentiated in the following way (e.g. see Martin \& Rose, 2008; Gardner, 2012; Chapelle, 1998; Biber \& Conrad, 2009; Hyland, 2000): Genre characteristics refer to the sequencing of information that is characteristic of the type of text, whereas register refers to the distribution of linguistic features that occur throughout the text type. An example of genre is the IMRD structure of a lab report (Introduction, Methods, Results, Discussion); the term also refers to once-occurring or rare linguistic features that are characteristic to a type of text, such as starting a letter with "Dear [name]." On the other hand, a study of register features might find that the relative frequency of passive voice is higher in research articles than in personal letters, while the personal letters have a higher frequency of personal pronouns.

While the focus of genre analysis and register analysis differs, both aim to provide a better understanding of the function of language in a particular context. For example, a study of genre might analyze research articles for execution of the IMRD structure and would acknowledge the function of this structure: to make very detailed and complex ideas understandable to a large audience of readers through delineating the steps of a research project in chronological order, from providing necessary background information about the topic (introduction), the methods used to perform the experiment, the results of the experiment, and finally, a discussion of why the results matter. The analysis would also highlight how any deviations from the structure affected the 
readability of the text. Similarly, the register analysis would account for the findings of more non-passives and pronouns in letters by explaining that letter writers are likely to refer to themselves and their audience directly. While it is helpful from a pedagogical standpoint to understand to what extent ELL students employ genre conventions, for the present study I chose to focus attention on register knowledge, specifically the distribution of linguistic features in ELL writing, because I believe it will provide insight into an especially challenging aspect of learning to write in a second language at the university level. In the next section I will further explain how the concept of register relates to the present study.

\section{Register Variation}

The present study incorporates the concept of register in that it seeks to discover whether ELL students, when compared to L1 students, use certain linguistic features more or less frequently in their academic papers. University students in the U.S. regardless of first language learn academic registers throughout their education by reading published works and by writing in-school genres such as essays and research reports. However, the difficulty of learning these registers can be illustrated by the fact that many people who speak English as a first language never become proficient readers or writers of academic papers. ELL students may struggle even more with learning these registers because they have not been gradually exposed to academic English throughout their secondary school education, as L1 students have. In addition, ELL students in U.S. universities are regularly exposed to the conversational register of English and may incorporate their burgeoning knowledge of spoken English into their academic writing. 
Unless they have been directed by a teacher to do so, they likely have not thought about the situational context, purpose, and audience of academic writing and how it differs from that of face-to-face conversation. Even if students have a sense that everyday conversation and academic English differ, they may not have been taught which linguistic features to use and which to avoid when writing a paper for class. The importance of teaching ELL students about registers, which includes situational contexts, linguistic features, and their associated functions, is the pedagogical motivation for conducting the present study.

As mentioned before, registers are distinguished by the situations for which they are intended, as well as by the relative distribution of linguistic features they employ; a particular register will typically contain a higher frequency of certain features, while another register will have a lower frequency of these same features. The linguistic features analysis at the center of the present study relates to the study of register variation, in that it will examine and compare the distribution of features in the academic writing of the two learner groups, L1 and ELL students. This type of analysis requires the use of corpus linguistics, the branch of applied linguistics that has made it possible to analyze large samples of spoken and written texts with the goal of describing how language is actually used. The following section discusses corpus linguistics, and highlights past research that has utilized corpora to analyze the distributions of linguistic features in ELL and English L1 student writing. 


\section{Corpus Linguistics}

Corpus linguistics involves the use of a corpus, which is a large, principled collection of written and/or transcribed spoken texts, for large-scale analyses of naturally occurring discourse. Some corpora contain millions of words from multiple registers of English (Davies, 2008-), while others contain fewer words and focus on a smaller number of registers (Granger, 2003). Due to its capacity to efficiently analyze large numbers of texts, corpus linguistics has advanced the fields of linguistics and English language teaching in important ways. First, it has allowed for an empirical analysis of language, meaning that what is deemed appropriate language for a given context is informed by examples from authentic language use instead of by human perceptions (Biber \& Reppen, 1998). This has resulted in an increasingly more detailed and accurate understanding of how English language is actually used (Granger, 1998). What's more, empirical analysis of corpora "has enabled researchers to discover patterns of language usage that had previously remained hidden from view" (Breyer, 2011, p. 1). These patterns are analyzed not only quantitatively, but also qualitatively, as corpus linguistics also entails the analysis of the specific functions performed by language. The deeper linguistic knowledge generated by corpus studies has influenced the creation of new dictionaries (Biber et al., 1999; Gillard \& Gadsby, 1998), textbooks (Reppen, 2012), and teaching materials (Chang \& Kuo, 2011) that aim to provide students with an accurate and descriptive knowledge of the English language.

Evidence that corpus methodologies have advanced the field of linguistics can been seen in register analysis, which relies on corpus methodologies to better understand 
the patterns of English used in a given register. In a study which utilized corpora to study the variation between registers, Biber (1988) analyzed the co-occurrence of 67 linguistic features to create continuums of variation, called dimensions, which predict the differences between spoken and written registers. For example, on a continuum between spoken and written English, a higher type/token ratio (the number of unique words in a text divided by number of total words) corresponds with a lower frequency of private verbs, emphatics, amplifier adverbs, be as a main verb, and coordinating conjunctions, and vice versa. Biber explains that the latter group of features is indicative of interactive communication with a non-informational focus, while type/token ratio, co-occurring with several other features, is indicative of a text with a high informational focus, a great density of information, and the communication of information in a concise and precise way (pp. 104-5). Thus, academic writing typically demonstrates a higher type/token ratio because writers have had time to plan their ideas, choose their words carefully, and revise their choices to ensure that the words effectively convey the nuances of their ideas. In contrast, conversation has a lower type-token ratio since the constraints of on-line production mean that the speaker tends to use more commonly used words (Biber, 1988). These findings help explain how registers are dependent on the relative frequency of a co-occurring set of linguistic features. This study also illustrates how corpus-based studies can help explain patterns in language that are not obvious to the naked eye.

Corpus-based studies have compared the distributions of linguistic features in textbooks and published research articles (Conrad, 1996), student-produced versus professionally-produced texts (Shaw, 2009), and the writing of L1 versus the writing of 
ELL students (Hinkel, 2002). While corpus linguistics takes a variety of approaches to analyzing language, the approach most pertinent to the present study is as follows:

Researchers compile and tag a corpus of text samples and employ a concordancer to find all the examples (tokens) of a specific word or linguistic feature in the corpus. They then calculate the frequency rate of the feature in each text and perform inferential statistics to compare the frequency rates between the groups of texts (Gilquin, Granger, \& Paquot, 2007). Finally, the comparison of frequencies is combined with an analysis of how each group employs the feature in context, revealing the similarities and differences between the groups regarding how they understand the functions of the linguistic features. The applications of the findings of a corpus-based study depend on the text type being analyzed; when the analyzed texts are produced by university students (whether ELL or English L1), corpus-based research provides implications for which features to teach or reinforce at the university level, where students are expected to produce writing that increasingly meets professional standards. In the next section, I first introduce the different approaches used to study second language writing, and then focus in on corpus studies that compare the frequency of linguistic features in academic writing produced by ELL and L1 students.

\section{Studies of Second Language Writing}

There are many approaches to studying effectiveness in second language writing. They include: identifying the metacognitive processes that ELL students employ while writing and the strategies for helping students build metacognitive awareness (e.g. Ong, 2014; Yayli, 2011; Negretti \& Kuteeva, 2011); measuring cohesion and syntactic 
complexity in ELL writing (e.g. Ortega, 2003; Crossley \& McNamara, 2012; Kormos, 2011); analyzing theme/ rheme and information structure in second language compositions (e.g. Jalilifar, 2010; Wei, 2013; Rafiei \& Modirkhamene, 2012); testing the effects of teacher feedback or peer feedback on subsequent drafts of written work (e.g. Diab, 2010; Evans, Hartshorn, \& Strong-Krause, 2011; Nurmukhamedov \& Kim, 2010; Bitchener \& Knoch, 2010); and exploring use of collocations and metaphor in ELL writing (e.g. Laufer \& Waldman, 2011; Kathpalia \& Carmel, 2011).

The approach at the center of this study is analyzing frequency and function of linguistic features in student writing to find where they match the standard uses for academic writing and where they deviate. Most studies analyzing linguistic features in student writing utilize corpus methodologies; the rest of this section focuses on the results of these studies.

Employing the corpus-based approach to counting and comparing use of linguistic features (described in the last section), prior studies have found that L1 and ELL writing differs in many respects, including use of collocations and lexical bundles (Siyanova \& Schmitt, 2008; Chen, 2010), cohesive devices (Crossly \& McNamara, 2009; Hinkel, 2001), adverbial connectors (ie. for example, however; Altenberg \& Tapper, 1998), and hedging modals (Hyland \& Milton, 1997). As the present study analyzes a restricted set of linguistic features, the discussion of past research will focus on what is known about how these particular features are used in ELL writing: be as a main verb, predicative adjectives, private verbs and public verbs, it-clefts, type/token ratio, passive voice, 
perfect aspect, modal would, amplifying and emphatic adverbials, and modal verbs of necessity (the features are in bold below; refer to table 2.1 for examples of each feature).

Features of spoken English. In Hinkel's corpus-based analyses comparing the writing of L1 and ELL university students, a consistent finding is that the features employed by ELL writers are more akin to the spoken register than to the academic register, and that the use of these features lends a sense of simplicity and lack of quality to ELL writing. Features of the spoken register include $\boldsymbol{b} \boldsymbol{e}$ as a main verb, predicative adjectives, private verbs and public verbs, all of which were found in statistically higher median frequency rates in the writing of ELL students compared to English L1 essays (Hinkel, 2003a). In contrast, an alternative sentence structure common to academic prose, the it-cleft, was found in the same study to be statistically more frequent in L1 writing than in ELL writing. Hinkel concluded that despite having received more college-level writing training than their L1 peers, the ELL writers employed less variety of syntactic structures and had a more limited lexicon. She suggested that ELL students receive more focused instruction in how to employ the features of the academic register.

Lexical diversity. Connected to the idea of limited lexicon is the feature type/ token ratio, which is a measure of lexical diversity and lexical specificity. Past research has shown that compared to L1 writing, ELL writing has a lower type/token ratio, which corresponds to a smaller range of vocabulary and the use of less specific words (Kormos, 2011; Crossley \& McNamara, 2009). Therefore, the inclusion of 
Table 2.1

Examples of Linguistic Features and Findings of Prior Research Regarding Frequency of Features in Student Writing.

\begin{tabular}{|c|c|c|}
\hline Feature & Examples & Findings of Prior Research \\
\hline Public verbs & agree, mention, present & Higher frequency in ELL writing; associated with conversation (Hinkel, 2003a) \\
\hline Private verbs & accept, consider, find & Higher frequency in ELL writing; associated with conversation (Hinkel, 2003a) \\
\hline Amplifier adverbs & $\begin{array}{l}\text { always, even (+adj), } \\
\text { very, well }\end{array}$ & $\begin{array}{l}\text { Higher frequency in ELL writing (Hinkel, 2003b); heightened feeling associated } \\
\text { with conversation (Biber, 1988); ELLs overstate the importance of an assertion } \\
\text { (Lorentz, 1998) }\end{array}$ \\
\hline $\begin{array}{l}\text { Emphatics (adverbs } \\
\text { and adjectives) }\end{array}$ & $\begin{array}{l}\text { complete, completely, } \\
\text { indeed, such a (+noun) }\end{array}$ & $\begin{array}{l}\text { Higher frequency in ELL writing (Hinkel, 2003b); heightened feeling associated } \\
\text { with conversation (Biber, 1988); ELLs overstate the importance of an assertion } \\
\text { (Lorentz, 1998) }\end{array}$ \\
\hline Be as a main verb & the wife was pregnant & Higher frequency in ELL writing; associated with conversation (Hinkel, 2003a) \\
\hline $\begin{array}{l}\text { Predicative } \\
\text { adjectives }\end{array}$ & the wife was pregnant & Higher frequency in ELL writing; associated with conversation (Hinkel, 2003a) \\
\hline Necessity modals & $\begin{array}{l}\text { must, have to, should, } \\
\text { need to, ought }\end{array}$ & $\begin{array}{l}\text { Higher frequency in writing of East Asian ELL students than in English L1 student } \\
\text { writing (Hinkel, 2009); same found in Swedish ELL students Aijmer (2002); } \\
\text { attributed to differences in cultural values and a more direct style of persuasion. }\end{array}$ \\
\hline Modal would & they would stand up & $\begin{array}{l}\text { ELL students underused it; need it for depersonalized or objective writing (Hinkel, } \\
\text { 2004) }\end{array}$ \\
\hline Perfect aspect & frogs have been found & $\begin{array}{l}\text { ELL students underused it; need it for depersonalized or objective writing (Hinkel, } \\
\text { 2004) }\end{array}$ \\
\hline Passive voice & children are affected & $\begin{array}{l}\text { ELL students underused it; need it for depersonalized or objective writing (Hinkel, } \\
\text { 2004) }\end{array}$ \\
\hline $\begin{array}{l}\text { Reduced adjective } \\
\text { clauses }\end{array}$ & $\begin{array}{l}\text { The authors listed in the } \\
\text { citation were students }\end{array}$ & Higher frequency in L1 writing (Hinkel, 2002) \\
\hline$i t$-clefts & $\begin{array}{l}\text { It is the senior women } \\
\text { who keeps track of them }\end{array}$ & $\begin{array}{l}\text { Higher frequency in L1 writing; a more advanced syntactic structure (Hinkel, } \\
\text { 2003a) }\end{array}$ \\
\hline Type/token ratio & $\begin{array}{l}\text { \# of unique words in first } \\
400 \text { words of text }\end{array}$ & $\begin{array}{l}\text { ELL writing has lower measure of lexical diversity and specificity than L1 writing } \\
\text { due to less developed word knowledge (Kormos, 2011; Crossley \&McNamara, } \\
\text { 2008) }\end{array}$ \\
\hline
\end{tabular}


type/token ratio in this study provides an additional dimension for better understanding the differences between the texts produced by the two student groups.

Tense and aspect. Another study by Hinkel (2004) compared the use of English tense and aspect across seven L1 groups. It was found that ELLs from East and Southeast Asian countries overused the past tense compared to English L1 students, often conveying their arguments through personal narrative. Arabic L1 students, on the other hand, used significantly fewer past tense verbs than English L1 students, using the present tense to make arguments based on sweeping generalizations and metaphors about common knowledge not directly related to the essay prompt. All groups of ELL writing underused or virtually ignored complex verb structures like passive voice, perfect aspect and use of modal would. These findings highlight the difficulties of ELL students in producing academic writing that sounds appropriately depersonalized and objective, even after they have received academic writing instruction. On the other hand, Hinkel (2004) found that even the most basic L1 writing demonstrated a wider grammatical range and employed the present tense significantly more frequently than all except the Arabic ELL group, using present tense for generalizations, observations, and descriptions in accordance with the conventions of academic prose.

Adverbial markers. In a study of adverbial usage in L1 and ELL writing, Hinkel (2003b) found that ELL students of all L1 backgrounds in the study used amplifying and emphatic adverbials at higher median frequency rates than freshman L1 university students. These adverbials have an interpersonal function, marking "heightened feeling," and thus are more frequent in spoken than written registers (Biber, 1988, p. 106). One 
explanation for the overuse may be that ELL students in U.S. universities receive more English input through conversation than through academic prose. The relative overuse of emphatics and other intensifier adverbs in ELL writing was similarly found in a corpusbased study comparing the writing of German and British students at both the high school and university levels (Lorenz, 1998). German high school students used the highest frequency of intensifier adverbs, followed by German university students, then British high school students, and was used least by British university students. The author argues that the overuse in ELL writing was likely due to a lack of experience in academic writing which led ELL students to overstate the importance of an assertion. L1 and ELL use of intensifiers also differed in where they occurred in the sentence: ELLs tended to use adverbs as intensifiers in the theme of a sentence, which led to a heavy subject noun complex, while L1 intensified the adjectives in the more reader-friendly rheme position, "where one would expect to find the elements that are new, relevant, and noteworthy enough to be intensified" (Lorenz, p. 62).

Modal verbs of necessity. Research about the effect of topic on the frequency of modals in L1 and ELL writing found that high-level ELL students from China, Japan, and Korea used significantly higher frequency rates of necessity and obligation modals (must, should, ought to, have to, and need (to)) than did L1 students in four of six essay prompts given (Hinkel, 2009). All four of these topics prompted students to discuss socio-cultural values about roles of family members, while the other two topics relied less on cultural background. Hinkel attributed the higher rate of necessity modals in familyrelated topics to the rigid hierarchical family structure of East Asian cultures influenced 
by Confucianism. Another study of modal verb usage found similar results: Compared to English L1 students in British universities, Swedish L1 university students overused necessity modals in their academic English writing, "adopting a direct and emphatic style of persuasion" (Aijmer, 2002, p. 65). Additionally, the ELL and the English L1 students used must in different ways. While both groups of writers similarly used must for conveying logical necessity, must as personal obligation was found in ELL writing four times more frequently than in L1 writing. Usage also varied by topic, with a high number of should and must found in ELL essays about immigration and environmental policies; in these cases, the modals were used to convince the reader of the merits of a certain action, reflecting the "cultural norms of behavior or a moral code" of the writer (p. 65).

This section of the literature review presented an overview of past research that found differences between L1 and ELL writing with regards to the use of the linguistic features related to the present study. In corpus-based studies conducted by Hinkel and others, ELL writing has been found to contain higher frequencies of features related to conversation. These features include be as a main verb, predicative adjectives, private verbs and public verbs, and amplifying and emphatic adverbials. Higher frequency of necessity modals in ELL writing was attributed to cultural transfer. Meanwhile, features found to be underused in ELL writing are characteristic of the academic register: it-clefts, passive voice, perfect aspect and modal would. A high type/token ratio is also characteristic of academic text with an informational focus. In the final section of the 
literature review I introduce Hinkel (2002), a large-scale analysis of linguistic features in student writing which provides a basis for the current study.

\section{Hinkel's (2002) Study of L1 and ELL Writing}

Hinkel (2002) compared frequencies of 68 linguistic features in a corpus of 1,457 essays written by English L1 and ELL students from six L1 backgrounds studying in U.S. universities. The $\mathrm{L} 1$ writers were all first-year students enrolled at public and private universities in the U.S. They chose one of six prompts designed to elicit an argumentative or expository essay; the mean number of words per essay was 294 . The essays were written as a diagnostic test for placement into first-year composition courses. Thus, none of the L1 writers had received college level writing instruction at the time they composed the essays, and their experience with academic writing was assumed to be limited to what they had learned in high school English classes.

ELL writers were given the same essay prompts as the L1 writers for ease of comparison; the mean number of words per essay was 299 . They all had a high level of English language proficiency as demonstrated by their TOEFL scores. All were students at four-year universities in the U.S. and were enrolled in courses in their major at the time of the study. They had previously completed English language training in intensive English programs either in the U.S. or abroad, or in community college or in high school ESL programs in the U.S. The majority of them had transferred to their current universities as juniors after earning their associate's degrees from two-year community colleges. The rest were either first-year students or graduate students. As a group, the 
ELL writers had received a mean of 9.8 years of EFL or ESL instruction. Therefore, they had had more college-level academic writing experience than the writers in the L1 group.

The results of the analysis found 26 features that were used in significantly different frequencies between the L1 and ELL groups. Sixteen features associated with simplistic writing were found in the ELL texts at a median frequency rate statistically higher than that of the English L1 writing samples (Table 2.2); they included be-copula as a main verb, predicative adjectives, and public and private verbs. Ten features were more frequent in L1 writing samples, including passive voice, perfect aspect, and reduced adjective clauses. The 42 features that were not found in significantly different frequencies included personal and indirect pronouns, existential there, verb tenses (past, present and future), and modals of possibility and ability.

The results revealed that the writing of English L2 university students trained in academic writing was significantly less syntactically and lexically complex compared to the writing of native English speakers who had not received instruction in college-level writing. Hinkel concluded that by educating students of the pitfalls of simplistic writing, teachers could help students notice these features in their writing and correct them on their own using the strategies they had been taught. She provided practical examples for better preparing students to achieve the level of writing ability expected of them in their university courses. One such example was to present ELL writers with alternatives to the most commonly used public and private verbs.

While it is helpful to know which features ELL students used in lower or 
Table 2.2

Features of Text Found in Significantly Different Frequencies between Samples of L1 and ELL Writing (Hinkel, 2002)

\begin{tabular}{|c|c|c|}
\hline $\begin{array}{l}\text { Classes of } \\
\text { features }\end{array}$ & $\begin{array}{l}\text { Features with significantly higher } \\
\text { frequency rates in ELL texts }\end{array}$ & $\begin{array}{l}\text { Features with significantly higher } \\
\text { frequency rates in L1 texts }\end{array}$ \\
\hline Nouns & $\begin{array}{l}\text { interpretive nouns } \\
\text { vague nouns } \\
\text { assertive pronouns }\end{array}$ & $i t$-cleft \\
\hline Verbs & $\begin{array}{l}\text { public verbs } \\
\text { private verbs } \\
\text { expecting/ tentative verbs } \\
\text { modal verbs of necessity } \\
\text { be as a main verb }\end{array}$ & $\begin{array}{l}\text { perfect aspect } \\
\text { progressive aspect } \\
\text { predictive modal would } \\
\text { passive voice } \\
\text { present participles } \\
\text { past participles }\end{array}$ \\
\hline $\begin{array}{l}\text { Adjectives/ } \\
\text { Adverbs }\end{array}$ & $\begin{array}{l}\text { predicative adjectives } \\
\text { amplifiers } \\
\text { other adverbs (manner, conjunct, } \\
\text { and adjective/verb modifiers) } \\
\text { adverb clauses of cause }\end{array}$ & \\
\hline $\begin{array}{l}\text { Subordinate } \\
\text { clauses }\end{array}$ & & $\begin{array}{l}\text { reduced adjective clauses } \\
\text { reduced adverb clauses }\end{array}$ \\
\hline $\begin{array}{l}\text { Text-rhetorical } \\
\text { features }\end{array}$ & $\begin{array}{l}\text { phrase-level conjunctions } \\
\text { sentence-level conjunctions } \\
\text { (transitions) } \\
\text { exemplification markers (for } \\
\text { example) } \\
\text { emphatics }\end{array}$ & $\begin{array}{l}\text { fixed strings (idiomatic phrases and } \\
\text { collocations) }\end{array}$ \\
\hline
\end{tabular}

higher frequencies compared to L1 students, a limitation of Hinkel's study is that the features with significantly different frequencies were not examined more in depth to discover and compare the situations and meanings for which the two groups of writers employed these features in the context of their essays. The present study addresses the need to better understand the functions of the features employed in student writing in cases where L1 and ELL students' frequency of use is significantly different. 


\section{Summary and Research Questions}

The expectations of the academy and of students themselves make ELL writing an area of instruction and research that deserves attention if we as educators aim to maximize our opportunity to prepare students for academic success. The literature review introduced the importance of register knowledge in learning to write academic English and explained how corpus linguistics has been applied to study the frequency and use of linguistic features. Corpus-based studies have found many differences between L1 and ELL academic writing, but a major finding is that ELLs use a greater frequency of features associated with conversation, while using a lower frequency of those associated with academic prose. The present study is based on Hinkel (2002), but builds on those findings to better understand ELL writing in the specific context of Portland State University’s Intensive English Language Program, especially how it differs from L1 writing with regards to the frequency and function of linguistic features. Specifically, this study will address the following research questions:

1. Does the writing produced by English L1 undergraduate students and ELL students of English for Academic Purposes contain significantly different frequencies of the linguistic features found to be different in Hinkel (2002)?

2. For features with significant differences, in what ways do ELL and L1 students use these features differently in the context of their writing, and what do these differences reveal about students' academic writing skills?

The importance of the frequency differences will be interpreted with additional analysis of the features' use in order to provide suggestions for teaching academic writing. 


\section{Chapter 3-Methods}

This chapter describes the methodology of the study. The first section presents the context of the study; it describes Portland State University's undergraduate programs and the Intensive English Language Program, the two settings in which the analyzed essays were produced. The second section details the data collection process, and the third section describes the data analysis procedures.

\section{Context of Study}

This study, conducted at Portland State University (PSU) in Portland, Oregon, compared the writing produced by English L1 undergraduate students enrolled in a variety of courses in University Studies and 9 other departments, and the writing produced by English language learner students enrolled in Level 5 writing courses in the Intensive English Language Program (IELP) at PSU. Below I describe the various courses and programs through which students at Portland State University learn academic writing.

Writing at PSU. Portland State University is a public university in an urban setting. It is the largest university in Oregon, with nearly 30,000 students and over 200 degree programs from bachelor's to doctoral degrees ("Portland State University Facts," n.d.). Despite the university's size, the average class size in freshman courses is 24 students ("Profile," n.d.). While students come from all 50 states and 80 countries, 79\% of students are Oregon residents. PSU is the most racially diverse university in the state, 
with non-white students representing $38 \%$ of the student body. It is also economically diverse, with 59\% of students receiving financial aid ("Profile").

To ensure that students learn effective communication skills, the university has a writing requirement for all students pursuing a bachelor's degree ("NEW: University Writing Requirement," n.d.). For students entering as freshmen, the requirement is fulfilled through mandatory enrollment in a sequence of University Studies courses (this program is described below). Transfer students must take a combination of University Studies courses and composition courses (in the English department), or writing intensive courses (in other departments; “NEW: University Writing Requirement”). For example, students transferring into the Maseeh College of Engineering and Computer Science with between 30-59 credits are required to take Writing 121 College Writing, Communication 100, and six University Studies courses for fulfilment of the college's Arts and Letters and Social Sciences requirement (Maseeh College of Engineering and Computer Science, 2011). Thus, the primary avenue through which PSU students learn about academic writing is the University Studies program.

University Studies. University Studies is the general education program required for undergraduate students at Portland State University (except for Honor's College and some transfer students). According to the university website, the purpose of the program is to broaden students' knowledge of the diversity of human experience, ethics and social responsibility while improving upon the academic skills required at the post-secondary level (“University Studies Goals," n.d.). University Studies entails a year-long course in 
the first year, three term-long courses each during the sophomore and junior years, and the completion of a senior capstone course in which students contribute to the community outside the university: the Portland metropolitan area ("UNST Introduction," n.d.). Examples of courses in the University Studies program are "Race and Social Justice" and "Sustainability." Each course aims to develop the inquiry, critical thinking, and writing skills needed for success in higher level college courses. Students produce writing that represents several genres and sub-genres, including literary analysis, secondary research papers, reactions to a reading, and reports of first-hand experiences.

IELP. The Intensive English Language Program (IELP) is a 6-level academic English preparatory program that provides instruction in English language and study skills to prepare international students for success in undergraduate and graduate degree programs at U.S. institutions. In the fall of 2012, the first term that the ELL essays were collected, over 500 students were enrolled in the program. Of these, $53 \%$ of students were from Saudi Arabia and 6\% were from Kuwait (Arabic L1), 10\% were from China and 3\% were from Taiwan (Chinese L1), 10\% were from Japan (Japanese L1), 4\% were from South Korea (Korean L1), and the rest were from 34 other countries (IELP, 2013). The program is operated by Portland State University within the Department of Applied Linguistics. Before students begin taking courses in the IELP, they take a placement test which assigns them to a general ability level; if initially placed in the lowest level, it will take 6 terms, or 1.5 school years, for them to complete the intensive English program, provided that they achieve passing grades in every course. The lowest level is the Preentry Program (PEP), followed by levels 1-5. At each level students are required to take 
Speaking and Listening, Grammar and Writing, Reading, and an elective course (Intensive English Language Program, n.d.).

The writing courses in the two highest levels of the IELP (levels 4 and 5) are called Guided Research Writing and Independent Research Writing. The goal of these courses is to familiarize students with the process of writing a research paper so they will be prepared to write similar papers in future college courses. While level 4 lays the groundwork for formatting a research paper using a topic and sources chosen by the teacher, level 5 expands on these research-paper writing skills by requiring students to choose their own topic, collect and evaluate sources to ensure they are relevant to the topic, and create an original research question, culminating in an 8-10 page research paper (Smith, 2010).

Upon completion of level 5 coursework, IELP students often matriculate into a degree program at Portland State University and begin taking content courses with English L1 classmates. However, a full $40 \%$ of IELP students begin taking mainstream courses at PSU while concurrently enrolled in IELP levels 4 and 5 (B. Bolstad, personal communication, April 19, 2013). These students speak a language other than English as their first language and have been conditionally accepted into a degree program pending completion of the university's language proficiency requirement. Conditionally-admitted freshmen may take one 100- or 200-level PSU course per term while enrolled in IELP level 4 and 5 courses. Conditionally-admitted IELP students who have transferred to PSU from another university are allowed to take one 300-level course per term with permission from an advisor. 
COMPARISON OF LINGUISTIC FEATURES

Whether preparing to enter PSU courses or already taking them, students in level 5 writing are at a critical juncture in their education between English-language and content courses; it is at this point that ELL students most rely on the skills learned in the IELP. Because ELL students' academic work in PSU courses is compared to the work of their English L1 classmates who have been exposed to academic register of English through years of formal education, it is also at this point when the level of preparation provided by IELP courses becomes most apparent. This study seeks to compare linguistic features in the writing of two student populations that share or will soon share classrooms and professors, and whose writing skills will be in clear relief.

\section{Data Collection}

I analyzed thirty essays written by ELL students in the IELP level 5 writing course, and thirty essays by English L1 students written for 100-, 200-, and 300-level courses in the undergraduate departments described above. Essays in the two groups contained between 850 and 4000 words each, with an average length of 1838 words in the L1 corpus and 2220 words in the ELL corpus (see Table 3.1).

English L1 corpus. The samples of L1 writing were selected from the Portland State University Corpus of Student Academic Writing (Viking Corpus), a project within the Department of Applied Linguistics (see Albers, 2007). The Viking Corpus represents papers from many disciplines and from students at every level of the institution; all papers received an A or a B grade and fall into one of the following categories or subgenres of academic writing, as labeled by the Viking Corpus: art and 
Table 3.1

Average Words per Sample and Total Words in the L1 and ELL Corpora

\begin{tabular}{|l|l|l|}
\hline & Corpus of L1 writing & Corpus of ELL writing \\
\hline Average words per sample & 1874 & 2306 \\
\hline Total words in corpus & 56,210 & 69,178 \\
\hline
\end{tabular}

Table 3.2

Number of Samples from Each Department and Course Level in L1 Corpus

\begin{tabular}{|c|c|c|c|c|}
\hline Department & 100 level & 200 level & 300 level & Total \\
\hline University Studies & 9 & 1 & 0 & 10 \\
\hline International Studies & 0 & 1 & 3 & 4 \\
\hline Anthropology & 0 & 0 & 4 & 4 \\
\hline History & 1 & 2 & 0 & 3 \\
\hline Political Science & 1 & 0 & 2 & 3 \\
\hline Psychology & 0 & 0 & 2 & 2 \\
\hline Women's Studies & 0 & 0 & 1 & 1 \\
\hline English & 1 & 0 & 0 & 1 \\
\hline General Science & 0 & 1 & 0 & 1 \\
\hline Philosophy & 0 & 1 & 0 & 1 \\
\hline Total & 12 & 6 & 12 & 30 \\
\hline
\end{tabular}

literary analysis, empirical analysis, library research, narrative, personal opinion, reading reaction, reflection, and report. The corpus compiled for the current study includes 30 papers from the Viking Corpus. To ensure that the writing samples were as comparable to one another as possible, all papers were of the 'library research' sub-genre, the characteristic college writing assignment in the which the author cites secondary sources for information and does not collect original data (Albers, 2007). One-third of the essays were written for courses in the University Studies program, and the other two-thirds were written for 100, 200, and 300-level courses in a variety of departments (see Table 3.2). This collection is meant to represent the variety of courses that IELP students are currently taking or will take upon completion of the level 5 writing course. The 30 
English L1 papers were selected from the Viking Corpus based on the student L1 (English), course level (100-, 200-, and 300-levels), and length of sample (between 800 and 4000 words).

ELL corpus. The papers in the ELL corpus were written by students in the IELP level 5 Independent Research Writing course. To ensure comparability with the L1 corpus, the papers in this group were also of the library research sub-genre and received either an A or B grade. This sample was expected to capture the level of writing ability demonstrated by high-achieving students in the final term of this intensive English program. The 30 ELL papers were collected by Linnea Spitzer, an IELP writing instructor, for the purpose of conducting research on the characteristics of student writing. She received approval from the Human Subject Research Review Committee in the spring of 2012 (HSRRC \# 122234) and began collecting informed consent forms in the fall of 2012. Six classrooms were represented in the ELL samples: two sections each from the fall 2012, winter 2013, and spring 2013 level 5 Independent Research Writing course. Linnea Spitzer was the instructor in three of these sections; the teachers of the other sections varied, but the specific teacher was not expected to affect the frequency of features in student writing.

Table 3.3 presents an approximation of the various disciplines represented in the ELL corpus; because essay topics were chosen by the students, they reflect a variety of interests, from the humanities to business to computer science. Essay topics sometimes straddled two disciplines, such as sociology and psychology in the case of an 
Table 3.3

Examples of Essay Topics and Disciplines Represented in ELL Corpus

\begin{tabular}{|c|c|c|}
\hline $\begin{array}{c}\text { Disciplines of essay } \\
\text { topics }\end{array}$ & $\begin{array}{l}\text { No. of } \\
\text { essays }\end{array}$ & Example essay topics \\
\hline Sociology/Psychology & 7 & Video game addiction: effects on the individual and society \\
\hline Business & 7 & Marketing: the privacy concerns of behavioral targeting \\
\hline Environmental studies & 5 & The benefits of composting; Solar energy in Saudi Arabia \\
\hline International studies & 3 & The benefits of volunteering abroad; Reverse culture shock \\
\hline Education & 3 & The use of corporal punishment in US schools \\
\hline Public health & 2 & The public health benefits of Medicaid and recent changes \\
\hline History & 1 & The destruction of Kuwait by the Iraqi invasion of 1990 \\
\hline Engineering & 1 & How architectural design affects quality of life and mood \\
\hline Computer science & 1 & Common problems associated with internet browsers \\
\hline Total & 30 & \\
\hline
\end{tabular}

essay about sociological implication of the divorce rate in the U.S. and the psychological effects of divorce on the child. While ELL students wrote mainly about business, the environment, and education, L1 students wrote largely about anthropology, political science, international studies. The similarities between corpora are that both consist mainly of essays written within disciplines in the Liberal Arts, and there is also some overlap of topics (childhood trauma, reverse culture shock).

\section{Data Analysis Procedures}

I used concordancer technology and non-parametric statistics to conduct a quantitative analysis of selected linguistic features to determine whether they were used in significantly different frequencies between the 30 L1 and 30 ELL writing samples. The following section outlines the procedures for selecting features to analyze, counting the number of tokens of each feature, obtaining statistical results, and analyzing the use of each feature in context. 
Table 3.4

Features Analyzed for Frequency Rate in the Present Study

\begin{tabular}{|l|l|l|l|}
\hline Type of feature & Semantic classes & Structural classes & Interpersonal classes \\
\hline Verbs & $\begin{array}{l}\text { public, private, 'be' } \\
\text { as a main verb }\end{array}$ & $\begin{array}{l}\text { perfect aspect, passive } \\
\text { voice }\end{array}$ & $\begin{array}{l}\text { necessity modals, } \\
\text { modal would }\end{array}$ \\
\hline Adverbs/ adjectives & & predicative adjectives & amplifiers/ emphatics \\
\hline Clausal & $\begin{array}{l}\text { it-cleft, reduced } \\
\text { adjective clause }\end{array}$ & \\
\hline Phrasal & $\begin{array}{l}\text { phrase-level } \\
\text { coordination }\end{array}$ & \\
\hline Lexical diversity & type/token ratio & \multicolumn{3}{|l}{} \\
\hline
\end{tabular}

Selecting features. I selected features from those which were analyzed in Hinkel (2002). Hinkel's study found 26 features used in significantly different frequencies between L1 and ELL writing samples (see Table 2.2). For the scope of a master's thesis, I needed to narrow down the number of features to analyze. I chose a set of features that represent the variety of different parts of speech and semantic functions that Hinkel covered without repeating many features in any single category. I also chose the set to include some features found by Hinkel to be used in greater frequencies by ELL students and others found to be used in greater frequencies by L1 students. I settled on the 13 features listed in Table 3.4 (for examples of each feature, refer to Table 2.1). Because verbs are at the heart of the English clause (since a clause is built around the verb) the analysis included seven different verbs classes: the semantic classes of public verbs, private verbs, and be as a main verb; the interpersonal classes of necessity modals and modal would; and the structural classes of perfect aspect and passive voice. Passive voice includes all passivized constructions with and without a by-phrase, and includes post nominal modifier -ed participle clauses, which are referred to as reduced adjective clauses in the present study. The selected features also included the following classes of 
adjectives and adverbs: predicative adjectives, amplifier adverbs, and emphatics, which can act as both adverbs and adjectives with an interpersonal function. Finally, clausal and phrasal features included coordinating conjunctions, reduced adjective clauses (postnominal modifiers with past and present participles), and the it-cleft, which is a marked structure characteristic of academic writing. An additional feature not of semantic, structural, or interpersonal relevance, type/token ratio, is a measure of lexical specificity and diversity and has been used for comparing the breadth of vocabulary employed in the spoken and written registers (Biber, 1988), as well as in the writing of English L1 and ELL university students (Kormos, 2011). Another motivation for my choice of features was to discover whether the ELL essays in the present study corroborated Hinkel's finding that ELL writing contained more features typical of conversation than did L1 writing. Therefore, I made sure to include the conversational features found to be more frequent in ELL writing: be as a main verb, predicative adjectives, private verbs, public verbs, and amplifiers/ emphatics (Hinkel, 2003a; 2003b).

Coding of features. Each writing sample was grammatically tagged with the Biber tagger (see Biber, Conrad, \& Reppen, 1998; Biber, 2006), which coded each word by its part of speech and, in some cases assigned a more specific classification for semantic class or other subcategory distinction. I used MonoConc Pro 2.2 concordance software (Barlow, 2004) to count each feature. In order to get the most accurate count, I used the word lists provided in Hinkel (2002) and searched for each of the words subsumed under the following categories: private verbs, public verbs, amplifiers, emphatics, modal would, necessity modals, it-cleft, and phrase-level coordination. 
Monoconc Pro produced a list of all of the tokens of a searched word, and I went through each list to check that each word was in fact an example of that feature. For example, when I performed a text search for thought, the past tense of the private verb think, I had to check each token found by the concordancer to be careful that I only counted the tokens of thought as a verb and not the tokens of the noun thought. I counted the following features by searching for their tags: predicative adjectives, $b e$ as a main verb, passive voice, perfect aspect, and reduced adjective clauses. To ensure accuracy, I searched each document thoroughly for tokens that were mis-tagged, and adjusted counts accordingly. For example, as I checked that each token of $b e$ as a main verb was correctly tagged, I also checked that tokens of predicative adjectives, which co-occur with this feature, were also all tagged correctly, and included the tokens that had not been identified into the total count of predicative adjectives.

The decisions about which tokens to include in each feature count were mainly based on distinctions made by Hinkel (2002) and several reliable English grammars (Biber et al., 1999; Biber et al., 2002; Quirk et al., 1985). Most features were easy to categorize following Hinkel's system of categorization. However, certain items required clearer operational definitions or slight modifications of categories. For example, I counted too in both too strong and too much strength as an amplifier, even though one too precedes an adjective and the other precedes a noun. While Hinkel only counted too preceding an adjective, I chose to count both so that I would not get a skewed count in case one student group tended to use the amplifier with adjectives while the other tended to use it with nouns. In another example, Hinkel (2002) counts amplifier adverbs and 
emphatics as separate categories, but after research into the differences and similarities between the two categories, I decided to count these as one feature, since several of the words on Hinkel's lists overlapped the two categories, and because their interpersonal functions are almost identical (Biber et al., 1999).

Quantitative analysis. To ensure an accurate count of each feature, I counted and re-counted the tokens in each essay. I then normed the frequency rates per 1000 words to provide a consistent basis for comparisons of texts of different lengths. The one exception, type/token ratio, was not normed per 1000. Instead, I followed the directions of Biber (1988) and counted the number of types in the first 400 words of each text and then divided this number by 400 . This technique was used to prevent skewing of the type/ token ratio when comparing texts of varying lengths.

I then compared the normed frequency rates of each feature in L1 and ELL writing samples by using non-parametric statistics. A non-parametric test was appropriate because of the non-normal distribution of the data. Based on the data analysis procedures of Hinkel (2002, pp. 66-71), I used the Mann-Whitney $U$ test to compare the ranks below and above the median frequency rate for each feature in each essay, between groups. I compared the medians of each data set instead of the means because a comparison of the means would result in any outliers heavily affecting the average frequency of a feature. I utilized SPSS statistical software to conduct the inferential statistics to compare the two groups' median frequency rates for each feature. 
COMPARISON OF LINGUISTIC FEATURES

Analyzing use of features. After obtaining the statistical results of the frequency analysis, I compared concordance listings of the two corpora to find the typical discourse contexts in which each of the significantly different features were used. Using grammar reference books to identify and classify the standard functions of a feature, I looked through examples from the two corpora to determine whether the feature was used similarly in L1 and ELL writing. I also looked for examples in which the feature was used in alternate ways apart from the typical functions. I noted whether the feature was used in a semantically different way or for different discourse functions between groups, and included this information in the results and discussion section.

Answering the research questions. To answer the first research question, about features found in significantly different frequencies between the two corpora, I compared the statistical results of the Mann-Whitney U tests for each feature between groups to find the features that had significantly different median frequency rates. To answer the second research question, about the different ways that the two groups used the significantly different features, I used the analysis described above to better understand how ELL and L1 essays employed each feature in context. The following chapter presents the results of the analysis and a discussion of the findings. 


\section{Chapter 4-Results \& Discussion}

This chapter presents the results and discussion of the analysis. It begins with the statistical results of the Mann-Whitney $U$ tests and a discussion of the median frequency rates and ranges of the two data sets, English Language Learner (ELL) and English First Language (L1). The second part of the chapter discusses how ELL and L1 students used the linguistic features differently in context.

\section{Results of Frequency Analysis}

Statistical results. Of the 13 features studied, the results of the Mann-Whitney U test show that five features were used in significantly different frequency rates between the two student groups: modal would, perfect aspect, passive voice, reduced adjective clause, and it-cleft (Table 4.1). These five features were used in higher frequency rates by English L1 students compared to use by ELL students. In addition, the L1 essays demonstrated a significantly higher type/token ratio than that of the ELL essays. None of the analyzed features had a significantly higher use by ELLs. The six significantly different features will be discussed in the Feature Use in Context section, with examples of how the two student groups differed in their use of these features.

The following features were not used in significantly different frequency rates: public verbs, private verbs, copula be as a main verb, modals of necessity, amplifiers/emphatics, predicative adjectives, and coordinating conjunctions (Table 4.2). 
Table 4.1

Test Statistics for Features with Significantly Different Frequency Rates

\begin{tabular}{|l|l|l|l|l|l|l|}
\hline & would & perfect & passive & adj clause & it cleft & type/token \\
\hline $\begin{array}{l}\text { Mann-Whitney } \\
\text { U score }\end{array}$ & 230.00 & 299.00 & 149.00 & 203.50 & 264.00 & 277.50 \\
\hline $\begin{array}{l}\text { Asymp. Sig. } \\
\text { (2-tailed) }\end{array}$ & $0.001^{*}$ & $0.026^{*}$ & $0.000^{*}$ & $0.000^{*}$ & $0.000^{*}$ & $0.011^{*}$ \\
\hline
\end{tabular}

$* 2$-tailed $p \leq 0.05$.

Table 4.2

Test Statistics for Features That Did Not Have Significantly Different Frequency Rates

\begin{tabular}{|l|l|l|l|l|l|l|l|}
\hline & public & private & be & nec-modal & amp & pred adj & coordin \\
\hline $\begin{array}{l}\text { Mann- } \\
\text { Whitney U } \\
\text { score }\end{array}$ & 379.00 & 445.00 & 429.00 & 373.00 & 416.00 & 408.00 & 440.00 \\
\hline $\begin{array}{l}\text { Asymp. Sig. } \\
\text { (2-tailed) }\end{array}$ & 0.294 & 0.941 & 0.756 & 0.255 & 0.615 & 0.535 & 0.882 \\
\hline
\end{tabular}

Medians and ranges. For the features whose frequencies were not statistically significant, the medians were very similar between the two groups, with a difference of less than 1 word per 1000 for all but coordinators, which had a difference of 1.83 words/1000 (Table 4.3).

Except for the case of modal would, the ranges for frequency rates between ELL and L1 essays are similar for each feature. What's more, the ranges tend to be larger than the medians, showing a large difference between the highest and lowest frequency rates in the essays of both student groups. This demonstrates the diversity of use of the features by students within each group. The one exception, modal would, with a range of 7.07 for ELL and 21.15 for L1, reflects extreme outliers in the L1 essays; without these outlier frequencies, the range for modal would would be around 7.0, which mirrors the ELL range. 
Table 4.3

Median Frequency Rates per 1000 Words (Except Type/Token Ratio) and Ranges for All Features

\begin{tabular}{|l|l|l|l|l|}
\hline & ELL median & ELL range & L1 median & L1 range \\
\hline public verbs & $\mathbf{7 . 3 4}$ & 12.63 & $\mathbf{6 . 9 9}$ & 12.63 \\
\hline private verbs & $\mathbf{1 2 . 3 0}$ & 27.45 & $\mathbf{1 1 . 8 8}$ & 23.84 \\
\hline be-main verb & $\mathbf{2 1 . 5 0}$ & 24.37 & $\mathbf{2 1 . 8 5}$ & 23.67 \\
\hline necessity modal & $\mathbf{3 . 7 8}$ & 10.04 & $\mathbf{2 . 0 1}$ & 8.26 \\
\hline modal would & $\mathbf{0 . 5 3} *$ & 7.07 & $\mathbf{2 . 2 5}^{*}$ & 21.15 \\
\hline perfect & $\mathbf{2 . 9 3} *$ & 12.16 & $\mathbf{5 . 4 8}^{*}$ & 14.77 \\
\hline passive & $\mathbf{1 1 . 5 1}^{*}$ & 18.23 & $\mathbf{1 8 . 4 3}^{*}$ & 21.07 \\
\hline adj clause & $\mathbf{2 . 2 0}$ & 8.39 & $\mathbf{5 . 2 1}$ & 12.52 \\
\hline amplifier & $\mathbf{7 . 6 0}$ & 14.28 & $\mathbf{8 . 3 0}$ & 16.05 \\
\hline adj predicative & $\mathbf{1 0 . 3 1}$ & 15.80 & $\mathbf{9 . 4 3}$ & 12.87 \\
\hline coordinator & $\mathbf{3 7 . 8 7}$ & 36.47 & $\mathbf{3 6 . 0 4}$ & 39.02 \\
\hline it-cleft & $\mathbf{0 . 0 0}$ & 0.93 & $\mathbf{0 . 0 0} *$ & 2.11 \\
\hline type/toke ratio & $\mathbf{0 . 2 8} *$ & 0.15 & $\mathbf{0 . 3 7} *$ & 0.16 \\
\hline
\end{tabular}

*2-tailed $p \leq 0.05$.

A comparison to the findings of Hinkel (2002). All of the features that I found

to be used in higher frequencies in the L1 corpus than in the ELL corpus were consistent with Hinkel's (2002) findings. In contrast, all of the features that were not significantly different in the present study were found by Hinkel to be significantly more frequent in ELL essays; Hinkel explained that they were also more common in conversation. Her conclusion was that ELL student writing was more like spoken English and less like the academic written register than L1 student writing. However, the results of the present study show no evidence that ELL students use these "conversational" features more frequently than L1 students. The median frequencies of each of these features were much lower in the ELL writing of the present study, compared to the frequencies found in the ELL writing of Hinkel's study.

\section{Feature Use in Context}


In this section, I present how ELL and L1 students used each of the significantly different features in the context of their essays in order to illustrate how students understood the features' functions in similar and different ways.

Modal would. An analysis of the usage of would in student writing resulted in three findings:

I. The essays employed four different meanings of would, and the frequency of use for each meaning differed between L1 and ELL groups.

II. Essay topic did not affect the frequency rate of would in general. However, high outlier frequencies of would were attributed to the essay topic.

III. Both groups of essays contained errors: L1 essays employed non-standard uses of would and ELL essays contained ungrammatical uses of other modals in cases where would was obligatory.

I. The meanings of would and their frequencies in ELL and L1 essays. Hinkel describes would as a lexically and syntactically complex modal verb, whose "meanings are ambiguous and variable, depending on the context" (2002, p. 111). An analysis of feature use in context found 4 distinct meanings of would in the student essays. A closer look at the frequencies of each meaning revealed that L1 students used the various meanings of would in a more evenly distributed manner, while ELL students predominately used just two meanings: as a hypothetical event/state or as a politeness marker (Table 4.4). Below, I discuss each meaning in turn; refer to Table 4.4 for examples in student writing. 
Table 4.4

Percentage of Use and Examples of would by Meaning

\begin{tabular}{|c|c|c|c|c|}
\hline Meaning of would & L1 example & L1 \% & $\begin{array}{l}\text { ELL } \\
\%\end{array}$ & ELL example \\
\hline $\begin{array}{l}\text { 1. hypothetical event } \\
\text { or state } \\
\text { (with or without a } \\
\text { conditional structure) }\end{array}$ & $\begin{array}{l}\text { If these slaves of human } \\
\text { trafficking knew and } \\
\text { believed that they were } \\
\text { created equally ...they } \\
\text { would stand up and fight } \\
\text { back. [310082] }\end{array}$ & $48 \%$ & $68 \%$ & $\begin{array}{l}\text { In contrast, girls would } \\
\text { be likely to stay if the } \\
\text { mother were employed } \\
\text { in either a professional } \\
\text { or intermediate } \\
\text { occupation. [210130] }\end{array}$ \\
\hline $\begin{array}{l}\text { 2. a future intention } \\
\text { expressed in the past } \\
\text { (past tense of will) }\end{array}$ & $\begin{array}{l}\text { However, Maryland felt } \\
\text { that the Articles would } \\
\text { take away many of the } \\
\text { freedoms that the states } \\
\text { exercised at that time } \\
\text { and would force the } \\
\text { states to relinquish their } \\
\text { land claims... } \\
\text { [310043hist] }\end{array}$ & $27 \%$ & $6 \%$ & $\begin{array}{l}\text {...reporters were told } \\
\text { by Mrs. Obama that } \\
\text { she would promote } \\
\text { breastfeeding } \\
\text { specifically among } \\
\text { black women, as part } \\
\text { of her campaign to } \\
\text { lower the children } \\
\text { obesity. [210139] }\end{array}$ \\
\hline $\begin{array}{l}\text { 3. a habitual or } \\
\text { characteristic } \\
\text { behavior, especially } \\
\text { one that occurred in } \\
\text { the past (Biber, et al., } \\
\text { 1999) }\end{array}$ & $\begin{array}{l}\text { Indeed, in some } \\
\text { situations, they would } \\
\text { even help in threatening } \\
\text { other Muslim women } \\
\text { who had not yet donned } \\
\text { the robes. [320036anth] }\end{array}$ & $13 \%$ & $5 \%$ & $\begin{array}{l}\text { When the couple knew } \\
\text { the wife was pregnant } \\
\text { with a baby girl, they } \\
\text { would abandon this } \\
\text { baby so they would } \\
\text { have another chance to } \\
\text { get a boy. [230131] }\end{array}$ \\
\hline $\begin{array}{l}\text { 4. politeness or } \\
\text { tentativeness } \\
\text { common with } \\
\text { requests and offers } \\
\text { (Quirk et al., 1985) }\end{array}$ & $\begin{array}{l}\text { In closing, I would like } \\
\text { to reiterate the argument } \\
\text { that rights and morality } \\
\text { are simply the result of } \\
\text { behavioral evolution. } \\
\text { [310043ph]. }\end{array}$ & $1 \%$ & $13 \%$ & $\begin{array}{l}\text { That means, mother } \\
\text { who tried breastfeeding } \\
\text { for her son found } \\
\text { perfect and significant } \\
\text { benefits for her baby, } \\
\text { so she would like to } \\
\text { share it with other } \\
\text { mothers. [210139] }\end{array}$ \\
\hline $\begin{array}{l}\text { Ungrammatical use } \\
\text { or unintended/ } \\
\text { inappropriate } \\
\text { meaning }\end{array}$ & $\begin{array}{l}\text { The advantage of having } \\
\text { living quarters close to } \\
\text { the porting system would } \\
\text { allow the natives to have } \\
\text { a first and more direct } \\
\text { contact with those } \\
\text { arriving in the area to } \\
\text { conduct trade. [320087] }\end{array}$ & $13 \%$ & $13 \%$ & $\begin{array}{l}\text { Spending time with } \\
\text { peers changes their } \\
\text { habits remarkably } \\
\text { easily, and it would } \\
\text { have some advantages } \\
\text { and disadvantages. } \\
\text { [210130] }\end{array}$ \\
\hline
\end{tabular}


1) To convey a hypothetical event or state: The majority of tokens in both L1 and ELL essays conveyed this meaning. However, it represented a larger percentage of tokens in ELL essays (68\%) compared to L1 essays (48\%).

2) To describe a future intention expressed in the past: This meaning conveys the past tense of modal will. This meaning was used in a larger percentage in L1 essays $(27 \%)$ than in ELL essays (6\%).

3) To describe a habitual characteristic or behavior: L1 essays had a higher percentage of tokens with this meaning (13\%) compared to ELL essays (5\%). However, it should be noted that nearly three fourths of these tokens in the L1 corpus were from one essay, which had a high outlier frequency of would. This essay is discussed in the sub-section about non-standard uses of would.

4) To convey politeness or tentativeness: $13 \%$ of tokens in ELL essays used this meaning, even though this meaning is not typically used in the genre of academic writing. In contrast, only $1 \%$ of L1 tokens of would had this meaning.

The analysis of use of each meaning shows that this feature is indeed lexically and syntactically complex, and the findings reveal a discrepancy between how ELL and L1 students employ the four meanings of would.

II. Essay topic. The topic of a given essay did not predict a higher or lower frequency of tokens of would. This was evidenced by the fact that although there was some overlap between L1 and ELL essays in discipline and even specific topic, group frequency rates were still significantly different. For example, both corpora include an 
essay about reverse culture shock and several essays each that touch on the effects of childhood trauma. I analyzed essay topics in both groups to check whether they necessitated hypothetical situations (the meaning of would with the largest percentage of tokens in each group) and found that even ELL essays with a zero frequency rate of would contained if conditional structures co-occurring with other modals such as will, might, and should instead of would:

When a sojourner returns to his home countries, if he expects a happy return without assuming some amount of reverse culture shock, he could

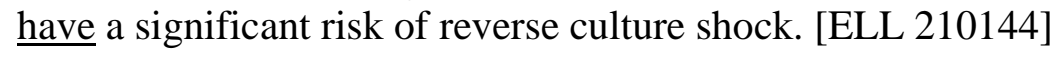

In most of these cases, the if dependent clause was used with a present tense verb and expressed a real condition, so the use of would to convey a hypothetical in the independent clause was not necessary.

In only one subset of essays did topic appear to correspond with frequency: 2 ELL and 2 L1 essays with high outlier frequencies of modal would. In both ELL essays, the topic dealt with a situation stemming from an environmental problem, and offered hypothetical solutions to that problem:

...if Saudi Arabia wanted to generate solar energy, they would have to create other jobs that are somewhat related to solar energy. [ELL 230153]

Because fishermen usually sell shark fin to restaurants, reducing the demand from restaurants would help a lot in curbing shark finning. [ELL 230151]

Likewise, essay topic was a factor in two L1 essays with outlier frequency rates of would; these essays presented hypothetical situations such as what would happen if the right to privacy were eroded [L1 320075] and what would be the implications for the animal 
Table 4.5

L1 Non-Standard Use of would and Revised Sentences

\begin{tabular}{|l|l|}
\hline Examples of misuse of would in L1 essay & Revised sentence \\
\hline $\begin{array}{l}\text { [1] It was in } 1843 \text { that John Couch would } \\
\text { move into the Oregon Territory and would be } \\
\begin{array}{l}\text { the one who was overseeing the building of } \\
\text { the wharfs. [320087] }\end{array}\end{array}$ & $\begin{array}{l}\text { [2] In 1843, John Couch moved into the } \\
\text { Oregon Territory and oversaw the building of } \\
\text { the wharfs. }\end{array}$ \\
\hline $\begin{array}{l}\text { [3] ...Portland has been notorious for } \\
\text { numerous floods. As flooding would occur, } \\
\text { they would need to clean up and clear out } \\
\text { their storage underground. As the repairs } \\
\text { were needed they probably would decide to } \\
\ldots . .320087]\end{array}$ & $\begin{array}{l}\text { [4] ..Portland was notorious for numerous } \\
\text { floods. As flooding occurred, they needed to } \\
\text { clean up and clear out their storage } \\
\text { underground. As the repairs were needed, } \\
\text { they probably decided to... }\end{array}$ \\
\hline
\end{tabular}

kingdom if humans had evolved differently [L1 310043ph].

III. Ungrammatical or non-standard usages. The third finding was that both groups of essays demonstrated ungrammatical or non-standard uses of would in the same proportions (13\% of tokens; see Table 4.4). While would was used more frequently in L1 essays, it appears that in some cases they over-used this device or used it in non-standard ways. Some of these non-standard uses did not make sense in the context of the essay, while others were standard for conversation but not for academic writing. Taken from an essay providing a direct narrative of the history of Portland, excerpt [1] in Table 4.5 illustrates the use of would as a future intention expressed in the past, which is a nonstandard usage in the context of this essay. Example [1] would only be the standard usage if at some point in the narrative, the writer explicitly took on the perspective of a bystander during Portland's founding. Instead, the accurate way to describe a historical fact is to use the simple past tense [2]. Would was also used in the same essay to convey a past habitual behavior [3]. However, because this essay is in the discipline of history and mainly relays past events, the typical choice is to use the simple past [4]. As the above 
examples also indicate, this essay overused would throughout, and thus represents the L1 university student who needs more instruction on when and when not to use this modal.

Another non-standard usage of would found in L1 essays has a hedging effect; this use is more typical in conversation than in academic writing. Students in both groups used would in this way, perhaps because they thought it gave an 'academic tone' to their assertions:

There is some recent evidence showing that the norepinephrine transporter also normally transports some dopamine as well, which would lead us to conclude that selective norepinephrine reuptake inhibitors may also increase dopamine transmission as well. [L1 320092]

This point makes this topic a more arguable topic because the social experience is a very important experience that would most certainly effect the academic development as well. [ELL 210145]

To illustrate how using would as a hedging device is appropriate for conversation, but not for academic writing, compare the above examples to samples of spoken English taken from the MICASE Corpus (Simpson, et al., 2002):

There's a Miles Davis version of that which also just incredibly unique in its own way and I would put this somewhere in that same ballpark.

It seems like it would be really critical to think through what the system wants to do and whether it's doing that.

The above comparison indicates that students are imitating conversation in their academic writing. This tendency in L1 essays was partially responsible for the higher frequency of would in the L1 corpus. 
To contrast the overuse of would in L1 essays, the errors in ELL essays related to the underuse of would when students opted to use different modals where would was obligatory. This resulted in ungrammatical sentences:

I always remember that my father told me he will always be there for me. [ELL 210157]

...Students must be encouraged of their studying if they perceive that their parents are also cooperated with schools... [ELL 210130]

This common error corresponds to the lower frequency rate of modal would in ELL essays. That ELL students opt to use other modals that they understand better may indicate that they have less mastery of how to use would than L1 students.

The above examples of student writing reveal that ELL students are still in the process of understanding the various meanings of would and acquiring when to use each meaning. At the same time, L1 students have broader understanding of the various meanings of would, but are still in the process of acquiring how to appropriately use it in their college essays.

Perfect aspect. The lower median frequency rate of perfect aspect in ELL essays corresponds to the use of the simple past tense in cases where the perfect was required. More specifically, there were three functions of prefect aspect used in L1 essays that were often misused in ELL essays: its use for events or states starting in the past and leading up to the present time; its use with certain adverbs for making the time period explicit; and its use for presenting the findings of past research that are still considered to be relevant. 
The first way in which L1 essays demonstrated the correct use of perfect aspect was to describe an event or state that started in the past and continues up to the present time (Biber et al., 2002, pp. 156-7):

He and the members of his non-profit health organization... have used their influence to change the health policies in numerous countries. [L1 330078]

The meaning of the above example is the members of the non-profit organization started to use their influence at some point in the past, and continue to use their influence today. This contrasts with some of the ELL essays, where the simple past was used instead of perfect aspect for this purpose:

Smoking is one of the most reasons of illness... According to the world health organization (2008) an estimated 57 million people died because of smoking. [ELL 210158]

The writer likely meant: ... an estimated 57 million people have died because of smoking, as smoking began to kill people at some point in the past and continues to kill people today. This error corresponds to the lower median frequency rate in ELL essays.

L1 essays also consistently used the perfect when the adverb accompanying the verb required it, but ELL essays did not. These adverbs add additional information about the preceding time leading up to the present, as demonstrated in the following L1 essay:

They also listened to the advice of Marc Askew who has recently done work in Southern Thailand. [L1 310106]

In the L1 corpus, all tokens of the adverb recently occurred with the present perfect, whereas in the ELL corpus, this adverb was also found with the simple past tense: 
COMPARISON OF LINGUISTIC FEATURES

According to Fagan, children whose parents divorced recently abuse drugs and alcohol much more than teenagers whose parents divorced during their early childhood. [ELL 210158]

A third way that L1 essays used perfect aspect correctly was for presenting the results of past research that are still considered valid at time of press, a common function of perfect in academic writing (Biber, et al., p.160):

Certain frogs have been found to perform the amazing feat of gender flipping when the sexual ratio among the species becomes disproportionate. [L1 310043ph]

In contrast, ELL essays sometimes used simple past for this purpose, likely because they do not know about this function of perfect aspect or follow prescriptive rules to use simple past to report research findings:

According to Lehrer (2011) scientists found out that old buildings make people stressed out even if were home relaxing and might be a contributing factor to having a heart attack. Some people get annoyed whenever they get in an old building. Therefore, they may not stand staying in that building and might have some serious health issues. [ELL 210143]

In the above example, the use of present tense in the second and third sentences indicates the continuing relevance of the statement made in the first sentence, old buildings make people stressed out, and therefore, the scientist's findings should be stated using the present perfect instead of the past tense.

Similar to the use of modal would, ELL essays demonstrated less mastery of when to use perfect aspect, and when not to. I have already shown examples of how the use of simple past where the perfect aspect is necessary led to ungrammaticality in ELL essays; in a final example, the use of perfect is ungrammatical or unnecessary in context: 
Parental involvement has many varieties of influence that encourage students' authentic actions...All students have communicated with their parents. When the children started to go to school, their parents' assistance is the most necessary to keep attending classes and enjoy the activities. [ELL 210130]

Based on the comparison of uses of perfect aspect between the two student groups, L1 essays contained correct and consistent use of perfect aspect, while ELL essays did not demonstrate mastery of this feature. Perfect aspect conveys sometimes subtle differences in meaning from simple aspect, and ELL students likely need additional practice with using perfect aspect in their academic writing.

Passive voice $^{1}$. The lower median frequency rate in ELL essays corresponds to two prevalent errors: the violation of information structure and the ungrammatical use of another verb form where passive was required. A third factor, essay topic, did not appear to have an effect on the frequency rate of this feature.

Understanding the use of passives requires understanding typical information order in English. The principle of information structure describes the typical order of information in a clause: The subject position contains previously given information, while the predicate contains new information. Presenting information in this way makes it easier for the reader to process the information and to understand the relationships between the given information and each of the new ideas as they are presented in the text. To perform this discourse function, the subject remains in the initial position in the clause

\footnotetext{
${ }^{1}$ As described in the methods chapter, passive voice includes all passivized constructions with and without a by-phrase, and includes post nominal modifier -ed participle clauses, referred to as reduced adjective clauses in the present study.
} 
as it changes from the agent of an action (active voice) to the recipient of an action (passive voice):

Pre-colonization Native Americans used more of an indentured servant system which, while forced on captives, often ended in integration of the captive into the tribe that they served. [No such practice] was seen in Anglo-American slavery where slaves were considered possessions as were their children and so on. [L1 330036]

The noun phrase in the bold font indicates the referent of the underlined verbs. After appearing as new information in the predicate of the first clause, indentured servant system stays in the subject position as the given information of subsequent clauses, leading to the newer information being presented at the end of each clause. As new information is presented about the indentured servant system, the subject goes from being the recipient of the action (passive verb found in a reduced adjective clause structure), to the agent of the active verb ended, and then back to the recipient of seen (bracketed words indicate the synonym for indentured servant system). This flow of information presents the new information in the predicate position (what the reader needs to know about indentured servant system) while the topic stays in subject position.

The findings of the study show that L1 essays generally used passive voice correctly to perform the standard discourse function of this feature: ordering information according to the principle of information structure by keeping a consistent subject as it changes between agent of an action and recipient of an action (Biber et al., 1999).

In contrast, ELL essays tended to use active voice instead of the passive in places where passive voice would have allowed this ordering of information. This led to the violation of information structure, and in some cases, ungrammaticality. This violation 
Table 4.6

Violation of Information Structure in ELL Student Writing

\begin{tabular}{|c|c|}
\hline Examples from ELL essay & Revised sentence following information structure \\
\hline $\begin{array}{l}\text { [5] Not just impact in social life might } \\
\text { affect children after divorce but also } \\
\text { emotional problem play big role in their } \\
\text { suffering. [210158] }\end{array}$ & $\begin{array}{l}\text { [6] After a divorce, not only are children affected } \\
\text { in their social lives, but they may also suffer from } \\
\text { emotional problems. }\end{array}$ \\
\hline $\begin{array}{l}\text { As a result [of parental pressure], some } \\
\text { children in China are suffering from } \\
\text { depression and many emotional } \\
\text { problems. The education system also } \\
\text { exposes children to stress and pressure. } \\
\text { They rarely enjoy their study process. } \\
\text { Children are busy preparing for their } \\
\text { exams all the time. [230131] }\end{array}$ & $\begin{array}{l}\text { As a result [of parental pressure], some children } \\
\text { in China are suffering from depression and many } \\
\text { emotional problems. In addition, children are } \\
\text { exposed to stress and pressure by the education } \\
\text { system; they rarely enjoy their study process and } \\
\text { [ ] are busy preparing for exams all the time. }\end{array}$ \\
\hline
\end{tabular}

makes the ideas difficult for the reader to follow. In Table 4.6, the ELL example [5] has two different noun phrases which occupy the subject positions (underlined), while there is a reference to children in the predicate of each clause (bold). The new information emotional problem is in subject position of the second clause, which violates the principle of information structure for creating clarity and ease of reading. A more appropriate construction that follows this principle [6] places children in the subject position of both clauses, allowing the subject to switch from a passive to active voice (underlined) as new information about children is presented.

Further evidence of ELL students' lack of control of passive is that ELL students used ungrammatical devices where a passive construction was the grammatical choice:

However, child abuse can also be passing by to the next generation. [ELL 210157]. 
Instead of passive voice (child abuse can also be passed on to the next generation), the author uses the present progressive. The use of passive voice in this essay was well below the median frequency rate for the ELL corpus, even though the topic of this paper, the negative effects of having an absent father, lends itself well to use of the passive voice. Since children are the recipients of these negative effects, one would expect a passivized structure to be common when child or children is in the subject position. This shows that to some extent, ELL students are still in the process of mastering when to use passive voice, which may explain a lower frequency of use although their essay topics have just as much potential as L1 essay topics for passive constructions. The examples below illustrate ungrammatical constructions; in instances where the subject is ambiguous, it is not clear whether the student chose to use active voice instead of the passive, or attempted the passive but incorrectly left out the be auxiliary verb:

They will feel much panic if they involved into the outside world because they get harmed in that world. [ELL 210159]

That is why parents must take the step of treating their child once they abused. [ELL 210159]

Meanwhile, L1 essays employed standard academic uses of passive by conforming to information structure and creating an effect of impersonal detachment from a subject, conveying objectivity, and therefore accuracy, on the part of the writer (Hinkel, 2002):

Beta-blockers have been shown to retrain the sympathetic response in certain types of anxiety. [L1 320092]

In the above example, the writer used passive to present the statement as an objective fact detached from the humans who conducted the experiments and discovered the results; 
Table 4.7

\section{Examples of Ineffective Choices of Voice and Revised Sentences}

\begin{tabular}{|l|l|}
\hline Examples from student writing & Revised sentences \\
\hline $\begin{array}{l}\text { Furthermore, spam remains untargeted: } \\
\text { whether working or playing, domestic or } \\
\text { overseas, no regard is shown to the users } \\
\text { age, sex, interests, location, or computing } \\
\text { experience. [L1 310014] }\end{array}$ & $\begin{array}{l}\text {..whether working or playing, domestic or } \\
\text { overseas, spam shows no regard to the user's } \\
\text { age... }\end{array}$ \\
\hline $\begin{array}{l}\text { Absent father can affect the child many } \\
\text { ways and juvenile offender is just one of the } \\
\text { many consequences. [ELL 210157] }\end{array}$ & $\begin{array}{l}\text { Children with absent fathers are affected in } \\
\text { many ways, and [ ] becoming a juvenile } \\
\text { offender is just one of the many } \\
\text { consequences. }\end{array}$ \\
\hline
\end{tabular}

beta-blockers, the recipient of the action (they receive the actions entailed in scientific experiments), is the subject of the clause, while the agent (researchers or scientists), is omitted. The omission of an unimportant agent is another characteristic use of passive in academic writing, one which also allows for conforming to information structure (Biber et al., 2002, p. 168).

Concerning the possible effect of essay topic on frequency of use, both groups contained the same number of essays whose topics I expected would necessitate the use of passive; the fact that L1 essays have higher median frequency rate could either mean that L1 students overuse the passive voice, or that ELL students underuse this feature. Each of these possibilities is illustrated in Table 4.7, which highlights examples of where ELLs' choice of passive voice and L1s' choice of active voice led to ineffective sentences.

The examples of passive voice in student writing reveal that L1 essays keep a consistent subject to order information in accordance with the principle of information 
structure, which creates an easy to follow narrative; on the other hand, ELL essays tend to use active voice where passive would be appropriate, which leads to an ungrammatical sentence or an ineffective or difficult to follow narrative. However, L1 essays also make ineffective choices when choosing the passive over the active voice.

Reduced adjective clause. Two factors important for understanding ELL and L1 use of reduced adjective clauses are the choice between using a full or reduced adjective clause and the over-generalized use of certain verbs in reduced adjective clauses, which sometimes resulted in ungrammatical sentences.

When modifying a noun with a post-nominal participle clause, there are two choices: a full adjective clause or a reduced form. According to a corpus analysis of published academic writing, when participle clauses are an option, reduced adjective clauses are more commonly used than full adjective clauses (Biber et al., 2002, p. 293). This is likely due to the efficiency of using fewer words to convey the same meaning. In the present study, both groups made use of full and reduced adjective clauses with both ed and -ing participle clauses (Table 4.8). However, the higher frequency rate of reduced adjective clauses in the L1 corpus corresponds with a more consistent and accurate use of this feature in L1 essays compared to ELL essays. In contrast, I found many examples of ELL essays that used the full adjective clause where the reduced form was a more appropriate choice (see examples in Table 4.9).

A second factor in the use of reduced adjective clauses is that ELL students tended to use this feature in an idiomatic way with certain verbs, which often led to 
Table 4.8

Examples of Full and Reduced Adjective Clauses with-ed and-ing Participle Clauses

\begin{tabular}{|c|c|c|}
\hline Participle clause & Full adjective clause & Reduced adjective clause \\
\hline $\begin{array}{l}\text {-ed participle } \\
\text { clause }\end{array}$ & $\begin{array}{l}\text {...the Articles of Confederation, } \\
\text { which were drafted by John } \\
\text { Dickinson, were adopted by all of } \\
\text { the states except Maryland. [L1 } \\
\text { 310043hi] }\end{array}$ & $\begin{array}{l}\text { The first two authors listed in the } \\
\text { citation were both students of } \\
\text { Richard Schultes... [L1 310045] }\end{array}$ \\
\hline $\begin{array}{l}\text {-ing participle } \\
\text { clause }\end{array}$ & $\begin{array}{l}\text {.. that composting program might } \\
\text { help lower the cost of trash } \\
\text { disposal in areas which were } \\
\text { paying by weight. [ELL 210140] }\end{array}$ & $\begin{array}{l}\text {...the Agri-fin Mobile program aims } \\
\text { to provide low-income farmers as } \\
\text { well as to benefit people living in } \\
\text { poverty with financial services... } \\
\text { [ELL 210132] }\end{array}$ \\
\hline
\end{tabular}

Table 4.9

ELL Use of Full Adjective Clauses and Revised Sentences with Reduced Adjective Clauses

\begin{tabular}{|l|l|}
\hline $\begin{array}{l}\text { Example of full adjective clause from ELL } \\
\text { student writing }\end{array}$ & $\begin{array}{l}\text { Revised sentence with reduced adjective } \\
\text { clause }\end{array}$ \\
\hline $\begin{array}{l}\text { However, a survey, which was conducted by } \\
\text { Little \& Akin-Little with } 149 \text { teachers shows } \\
\text { a result that } 10 \% \text { of teachers... [210138] }\end{array}$ & $\begin{array}{l}\text { However, a survey conducted by Little and } \\
\text { Akin-Little with } 149 \text { teachers shows... }\end{array}$ \\
\hline $\begin{array}{l}\text { The two biggest aspects that are affected by } \\
\text { ecotourism are the environment and } \\
\text { indigenous people. [210137] }\end{array}$ & $\begin{array}{l}\text { The two biggest aspects affected by } \\
\text { ecotourism are... }\end{array}$ \\
\hline
\end{tabular}

ungrammatical sentences. Call, use, and need were used at a higher percentage of tokens of reduced adjective clauses in ELL than in L1 essays (Table 4.10). The over-generalized use of reduced adjective clauses with these verbs led to ungrammatical uses of this feature. The best example of this is the use of the verb call for identifying the name of a concept or product when a reduced adjective clause was not necessary (Table 4.11). In contrast, L1 essays had a higher percentage of tokens of reduced adjective clauses with the verbs found, given, and based, and all tokens were grammatical. 
Table 4.10

Verbs in Reduced Adjective Clauses with the Highest Percentage of Difference in Frequencies between ELL and L1 Corpora

\begin{tabular}{|c|c|c|c|}
\hline Verb & ELL \% & L1 \% & Example from student writing \\
\hline called & $11.9 \%$ & $3.7 \%$ & $\begin{array}{l}\text { He is willing to try new products and brands from } \\
\text { different country such as a drink called Taisun's Grass } \\
\text { Jelly Drink... [ELL } 210150]\end{array}$ \\
\hline used & $6.3 \%$ & $2.8 \%$ & $\begin{array}{l}\text {..progressive relaxation is the most common form of } \\
\text { relaxation used before visualization... [ELL 210133] }\end{array}$ \\
\hline needed & $3.2 \%$ & $0.5 \%$ & $\begin{array}{l}\text {...people should only pay for the equipment needed to } \\
\text { generate solar energy. [ELL } 210153 \text { ] }\end{array}$ \\
\hline found & $0.8 \%$ & $3.3 \%$ & $\begin{array}{l}\text {...cannabinods found in marijuana have been known to } \\
\text { relieve stress... [L1 320092] }\end{array}$ \\
\hline given & 0 & $3.3 \%$ & $\begin{array}{l}\text { They required that the aid given go to industrial and } \\
\text { agricultural development. [L1 310090] }\end{array}$ \\
\hline based & $0.8 \%$ & $2.8 \%$ & $\begin{array}{l}\text { The specialty coffee business was able to create new } \\
\text { markets for itself based around two identity indicators... } \\
\text { [L1 310071] }\end{array}$ \\
\hline
\end{tabular}

Table 4.11

Examples of ELL Essays with Unnecessary Use of Reduced Adjective Clause with Verb call and Revised Sentences

\begin{tabular}{|l|l|}
\hline Example from student writing & Revised sentence \\
\hline $\begin{array}{l}\text {...how prepared are new couples nowadays } \\
\text { to face the challenges of the oldest institution } \\
\text { called family, which has revealed so } \\
\text { problematic... [210158] }\end{array}$ & $\begin{array}{l}\text { f.how prepared are new couples nowadays to } \\
\text { face the challenges of the oldest institution, } \\
\text { family, which has revealed so problematic... }\end{array}$ \\
\hline $\begin{array}{l}\text { Jeff Bezos, who established Amazon.com } \\
\text { selected the name called "amazon" because } \\
\text { he hoped... [210149] }\end{array}$ & $\begin{array}{l}\text { Jeff Bezos, who established Amazon.com, } \\
\text { selected the name "Amazon" because he } \\
\text { hoped... }\end{array}$ \\
\hline
\end{tabular}

These examples demonstrate that ELL students have more to learn about using reduced adjective clauses accurately and effectively for academic writing.

It-cleft. This feature was found rarely in both corpora, with 25 tokens found in the L1 corpus, and only 3 tokens in the ELL corpus. While the median frequencies rates for both student groups were 0.00 , the ranges of frequency rates were 2.11 for L1 and 0.15 
for ELL. Where students chose an it-cleft construction, both ELL and L1 groups used it for the standard function; however one of two ELL students using this feature did not form it grammatically. The low frequencies suggest that most of the students in each group lacked knowledge about when and why to use this feature.

The discourse function of $i t$-cleft is to allow the writer to focus the reader's attention on the most important piece of information, which contributes to the cohesion of a text (Quirk et al., 1985). The first phrase of the it-cleft contains the focal element of the sentence, while the second phrase contains the background element:

In an ironic twist of fate, it was the US military that ushered Aristide back into the country... [L1 330078]

In the above example, the emphasis is placed on the US Military as agent of the actionthe fact that they were responsible (bold) —instead of emphasizing the action that they accomplished (underlined). In addition, the use of an it-cleft typically provides both a connection and a clear contrast between the information provided in the it-cleft sentence and the information that precedes it (Biber et al., 1999):

Culturally the men take a higher seat over women, but in actuality, the women control a great deal of the power within the house...In the matrilineal society of the Minangkabau, for example, it is the senior woman who keeps close track of genealogy and who ultimately decides the dispersal of land. [L1 320036an]

The information in the above it-cleft emphasizes that women $d o$ hold power in society (bold), which contrasts with the earlier statement about how men are perceived to have a higher status than women in this culture (underlined). In the investigation of how the student writers used $i t$-clefts, I found that each token in both student groups fulfilled the 
Table 4.12

Example from ELL Writing Where Use of it-cleft Would Strengthen Emphasis and Contrast and Revised Passage

\begin{tabular}{|c|c|}
\hline Example from ELL essay & Revised sentence with it-cleft \\
\hline $\begin{array}{l}\text { [7] Fashion industry is highly competitive but } \\
\text { the main factor to make the difference that } \\
\text { caused Louboutin stand out is his signature is } \\
\text { not his own name. On the contrary, one of his } \\
\text { signatures that can make billions of women } \\
\text { around the world fall in love with his luxury } \\
\text { high heels is simply the red sole. [210136] }\end{array}$ & $\begin{array}{l}\text { [8] It was not his name that made } \\
\text { Louboutin stand out in the highly } \\
\text { competitive fashion industry. On the } \\
\text { contrary, it was the red sole, his signature } \\
\text { feature, that made billions of women around } \\
\text { the world fall in love with his luxury high } \\
\text { heels. }\end{array}$ \\
\hline
\end{tabular}

discourse functions of creating emphasis and contrast. However, the infrequent use-14 of 30 L1 essays and 2 of 30 ELL essays used it-clefts - suggests that the majority of the students in each group do not have this grammatical device in their repertoire. One ELL essay contained two tokens, but both of these it-clefts were ungrammatical because they lacked the relative pronoun:

The basic eligible populations of getting long-term care are seniors and the disabled... As we know, it is not every senior and disabled person have eligibility. [ELL 210134]

Indeed, it is not every poor person can be called low-income people. Lowincome individuals must earn less than Medicaid requires. [ELL 210134]

The above examples show that while this particular student understood the discourse function of it-cleft, he or she had still not mastered how to form it correctly. Within the scope of this study, it is not possible to determine whether ELL students did not use itclefts because they had not learned about them, or they avoided them because they did not feel confident using them correctly.

It is important to note that students did use alternative devices to fulfill the discourse function of contrasting two ideas such as but, while, even though, and on the 
contrary. These were used with varied effectiveness, as shown in Table 4.12. The underlined words in example [7] highlight where the student attempts to add emphasis between contrasting ideas. However, I found that [7] was not effective in emphasizing that Louboutin is much more than just his name, or that the red sole was his most recognizable style. The use of an it-cleft adds emphasis in the way that the writer likely intended [8].

Of all the features found to be significantly different, the it-cleft construction was the least used by both groups of students, illustrating that this is not a feature that university students are accustomed to using in their writing. It should be noted, however, that this feature is relatively uncommon in published academic writing compared to the other features discussed in this study; Biber et al. (2002) found the frequency of it-clefts to be 600 tokens per 1 million words (equivalent to once in every four pages of an average academic book), compared to 1400 tokens of would, 3500 tokens of perfect aspect, and 20,000 tokens of passive verbs. Even the existential there, which is also an alternative clause structure, was found more than four times the frequency of it-clefts, with 2500 per 1 million words in academic writing. Thus, students should be cautioned to not overuse it-clefts in their writing. Nevertheless, it is a useful feature with a specific purpose in academic writing, and it will serve students well to learn how and when to use this feature to make their writing more effective.

Type/token ratio. This feature measured the breadth of vocabulary in each essay. As a group, ELL essays had a significantly lower type/token ratio than L1 essays, and therefore contained less lexical diversity and lexical precision than L1 essays. It is not 
Table 4.13

Number of Tokens of Three Open-Class Words and Their Percentage of Total Words in Two Essays about Reverse Culture Shock

\begin{tabular}{|c|l|l|l|l|}
\hline Word & \multicolumn{2}{|c|}{ ELL essay } & \multicolumn{2}{c|}{ L1 essay } \\
\hline & percentage & \# of tokens & percentage & \# of tokens \\
\hline culture & $3.12 \%$ & 60 & $0.84 \%$ & 15 \\
\hline shock & $2.08 \%$ & 40 & $0.56 \%$ & 10 \\
\hline reverse & $1.82 \%$ & 35 & $0.22 \%$ & 4 \\
\hline Total & $7.02 \%$ & 135 & $1.62 \%$ & 29 \\
\hline
\end{tabular}

surprising that English L1 students have a broader and deeper knowledge of English vocabulary than students whose English-medium education began in adulthood and who are still becoming familiar with the conventions of academic English. A comparison of vocabulary use in context revealed that L1 essays employed less repetition of vocabulary by using cohesive devices such as synonyms and demonstrative pronouns, which resulted in a higher type/token ratio for L1.

To compare the use of vocabulary between the two groups, I focused on two essays with the same topic: reverse culture shock. I compared the frequency of use of the three most common open-class words in the ELL corpus. Table 4.13 shows that the ELL use of the words reverse, culture, and shock (the three topic words) were a much higher percentage of the overall word count, compared to the use of the same words in the L1 corpus.

In the ELL essay about reverse culture shock, over $7 \%$ of total words were one of three topic words, whereas fewer than $2 \%$ of the words in the L1 essay were comprised of topic words. The reiteration of topic words throughout the essay was a common device used by ELL students to create a cohesive text: 
...lack of realistic image of returning is also one of the causes of reverse culture shock. If sojourners want to prevent getting reverse culture shock, they need to brace themselves for their return objectively. According to Martin (1984), sojourners expect different culture and some culture shock when they leave for a foreign country, so they can adapt easily. [ELL 210144]

The overuse of the phrases culture shock and reverse culture shock throughout the essay make the text seem repetitive and contributes to the low type/token ratio in this essay.

Meanwhile, the L1 essay has relatively fewer mentions of the topic words within the text, and instead employs other devices for creating cohesion:

Culture shock is when a student has difficulty transitioning into a new culture. Occasionally, these difficulties prove severe enough for the student that he or she is never able to come to terms with them. [L1 310036]

Instead of using the same words to refer back to the information of the first sentence (the topic words), the writer uses the demonstrative pronoun these and a synonym referring to culture shock (difficulties) to tie together the information in the two sentences.

Besides using cohesive devices, another way that L1 students increase type/token ratio is by using synonyms throughout the essay instead of relying on the same phrase every time an idea is reintroduced:

It is common for students to feel confused and out of place in their home country due to their personal growth, changed world views, and their newfound independence.

After spending as much as a year with a host family, students may also begin to see the world from a new perspective.

Students often acquire a broadened point of view from living and interacting with a host family and culture and want to share that with their families. [L1 310036] 
The phrases changed world views, new perspective, and broadened point of view are all different ways to express the same idea. In contrast, it seems that ELL writers reuse the same words instead of diversifying their vocabulary with synonyms. The following example from the ELL essay about reverse culture shock further illustrates this tendency:

What it comes down to is that the businessman did not expect any difficulty to fit in Israeli environment but expected a comfortable life. Even if the sojourner unconsciously expects a happy return but any difficulty, sojourners who are going to return soon should understand that they might not have the happy return which they imagine. [ELL 210144]

In the above example, with a word count of 56, there are 23 open-class words, yet 12 of these are repeats: derivations of expect and return have 3 tokens each, while difficulty, happy, and sojourner(s) each have 2 tokens. The total number of unique open-class words in this passage of 56 words is actually only 16 . The repetition of words instead of the use of cohesive devices and synonyms correspond to the significantly lower type/token ratio in ELL essays.

\section{Summary}

The first research question asked whether or not the writing of ELL students in the IELP and English L1 students at Portland State University contained significantly different frequency rates of the linguistic features that Hinkel (2002) found to be different between the two student groups. In this chapter I presented the results of the MannWhitney U tests, which answered the research question: There were in fact six linguistic features found in significantly lower frequencies in ELL essays than in English L1 essays. To answer the second research question, which sought to understand the 
differences in how students used each of the six significantly different features in their writing, I analyzed examples of each feature within ELL and L1 essays and compared how each group used the feature in the context of the essays. In the next chapter I will summarize the most important findings and discuss their implications for teachers and students. 


\section{Chapter 5- Conclusion}

The final chapter provides a summary of the findings presented in the results and discussion chapter, followed by the implications and applications of the findings to the teaching of academic writing to English language learners. The chapter concludes with a discussion of the limitations of the study and suggestions for future research.

\section{Summary of the Results}

In order to better understand the preparedness of students in the Intensive English Language Program to take undergraduate courses at Portland State University, this study sought to find differences between the frequencies and uses of 13 linguistic features in essays written by ELL students in the final level of academic English instruction and English L1 students in mainstream undergraduate courses. The analysis of the frequencies of linguistics features in L1 and ELL essays and their use in the context of student writing resulted in several interesting findings:

- Seven features were not found in significantly different frequencies: public verbs, private verbs, be as main verb, modals of necessity, amplifiers, predicative adjectives, and coordinating conjunctions.

- These features are associated with conversation and were the features that Hinkel (2002) found in higher frequencies in ELL writing. That this study did not find these features in significantly different frequencies between L1 and ELL essays means that ELL students in this study did not rely more heavily than L1 students on the 7 features typical of conversation. 
- Six features were found in significantly different frequencies between the two groups: modal would, perfect aspect, passive voice, reduced adjective clauses, itclefts, and type/token ratio.

- All of the features found to be significantly different were more frequent in L1 essays. These features are associated with published academic writing. For the most part, L1 students demonstrated mastery of these in their writing, while ELL essays contained ungrammatical usages of these features, or omitted them where they were obligatory. From these observations I concluded that ELL students were still in the process of learning how to use these features in their writing.

- Would was found in significantly lower frequencies in ELL essays than in L1 essays. ELL essays predominantly used two meanings of would, one of which, to convey politeness, is not a typical use in academic writing. Meanwhile, L1 essays used the four meanings of would in a more evenly-distributed manner. However, both groups of students used would in ungrammatical or non-standard ways in the same proportions. This shows that ELL students are still in the process of understanding the various meanings of would and acquiring when to use would, while both groups of students are still learning how to use this feature in their academic writing.

- Perfect aspect, passive voice, and reduced adjective clauses were used in significantly lower frequencies in ELL essays than in L1 essays. Based on an analysis of how each group used these features in context, it appeared that L1 essays used these features in accordance with the standard uses in academic 
COMPARISON OF LINGUISTIC FEATURES

writing. In contrast, ELL essays tended to use these features in ungrammatical or non-standard ways, and at the same time they used other features where perfect, passive, or reduced adjective clauses were obligatory or were stylistically a more appropriate choice.

- It-clefts were used in ELL essays with significantly lower frequency than in L1 essays, although they were used infrequently by both groups. While some students in both groups used this feature correctly for its standard purpose, the majority of students appeared to not have this feature in their repertoire. Instead, they used other devices for emphasizing a contrast.

- As a group, ELL essays had a lower type/token ratio than L1 essays. This corresponded with ELL essays repeating topic words to refer back to ideas in a text. In contrast, L1 essays used a greater breadth of vocabulary by utilizing demonstrative pronouns and synonyms instead of repetition to create cohesion, which corresponded to a higher type/token ratio in L1 essays.

While teachers of English-medium content courses may tend to see ELL papers as "weaker" than those written by L1 students, this weakness cannot be entirely explained by the lower frequency of use in ELL writing of the six features mentioned above. Based on the analysis of use of features in context, it seems unlikely that the underuse of these features alone have a global impact on the ELL essays, nor does it account for teacher perceptions that ELL papers are less effective; what affected the quality of the essay more noticeably was when ELL student used one of these features in an ungrammatical way, or in cases where another feature would have been more effective. In addition, rhetorical 
features are likely responsible for teacher perceptions of writing quality and effectiveness. An analysis of rhetorical features was beyond the scope of this study, but this is an area of future research and will be discuss later in the chapter.

An additional interpretation of the results addresses students' understanding of academic writing. The results show that ELL students are still in the process of acquiring certain features to use in their writing, namely modal would, perfect aspect, passive voice, reduced adjective clause, and it-clefts. While ELL students do use these features, they use them in noticeably different ways compared to the L1 students. ELL essays also had a significantly lower type-token ratio which means they must continue to develop their vocabulary and broaden their understanding of cohesive devices in academic writing to produce a higher quality of writing.

The results also offer implications for L1 student writing: Based on their essays, L1 students seemed to have acquired the uses of perfect aspect, passive voice, and reduced adjective clauses appropriate for academic writing. However, their use of would demonstrated a lack of appreciation of register, sometimes resembling usages typical of conversation instead of those typical of academic writing. In addition, they used it-clefts very infrequently, implying that they might need further instruction to better understand the value of employing this feature in their writing.

In comparing the findings of the present study with those of Hinkel (2002), on which the present study was based, both similarities and differences emerge. Both studies found significantly higher frequency rates of the following features in L1 essays: would, 
perfect aspect, passive voice, reduced adjective clauses, and it-clefts (type/token ratio was not analyzed in Hinkel, 2002). That the ELL essays in this study contained significantly lower frequencies of these features corroborates Hinkel's claim that ELL students have a narrower grammatical range than L1 students in their academic writing. However, because Hinkel did not go into much detail describing the context in which the two groups of students used the significant features, the present study contributes a deeper understanding of how ELL students use features typical of academic writing, and how closely these usages align with those in L1 student writing. These comparisons provide implications for how instructors can help ELL students further build their writing skills as students work towards becoming proficient in academic English.

The results of the current study differ from Hinkel's in that they did not reveal significant differences in the frequencies of features associated with conversation, which Hinkel found in higher frequencies in ELL writing (public and private verbs, be as a main verb, necessity modals, amplifiers, predicative adjectives, and coordinating conjunctions). It is important to note that the L1 and ELL essays in the present study contained lower frequency rates of these features than did the essays in Hinkel's study, meaning that PSU students demonstrated less use of conversational features in their academic writing than did the students in Hinkel's study. Some variability in results could be due to the six different L1 groups represented in Hinkel's study. The present study treated ELL writers as one group, not accounting for differences in features use between specific L1 groups. The differing results may also be explained by differences between the samples of student writing used in the respective studies. The samples of L1 
and ELL writing used in Hinkel's study were timed argumentative essays written as diagnostic tests; the high-pressure environment of a timed writing test requires the realtime mental processing associated with conversation, which may explain the conversational features found in ELL writing samples. In contrast, the writing samples in the present study were research essays that had been revised through multiple drafts and had presumably taken several weeks to write. As demonstrated by the similar frequencies of the aforementioned features in ELL and L1 writing, ELL students were likely alerted to any existing features of conversation in their essays during the writing process, and were given the chance to change them in accordance with appropriate academic language. Compared to the writing samples analyzed in Hinkel's study, the writing samples I analyzed were more representative of the writing that ELL students will be expected to produce in mainstream university courses: research essays written in multiple drafts. This is the type of writing taught in the specific context of Portland State's IELP to prepare ELL students for university coursework. In the next section, I discuss how the findings of this study could be applied to teaching academic writing.

\section{Applications for Language Teaching}

Because the purpose of this study is to learn more about the writing ability of students in Portland State University's IELP, it is my hope that the findings of this study will be relevant first and foremost to the instructors in the IELP, who will be able to refer to a statistical analysis of student writing for a better understanding about the features that ELL students underuse in their writing assignments. By shedding light on the gaps that exist between English L1 knowledge of academic writing and that of IELP students, the 
findings may be used by the IELP instructors and administrators to inform the content of the level 5 writing course, or influence the creation of materials and future textbooks for IELP writing courses. The student workers in the IELP Learning Center, who tutor IELP students in their academic work, will similarly be able to use the findings of this study to target certain features when a student come to them asking for help on their term paper. Below I offer some specific applications for teachers and tutors.

Modal would. The examples of student writing reveal that although L1 students seemed to have more knowledge than ELL students about how to use the various meanings of would, neither group demonstrated mastery of this feature in their academic writing. A tendency to predominantly rely on only two meanings of would, and many ungrammatical tokens of this feature show that ELL students are still in the process of acquiring when to use would and understanding its various meanings in general. At the same time, overuse and non-standard use of this feature in L1 essays show that L1 students are still acquiring how to convey precise meanings using would in their college essays. Therefore, both L1 and ELL college students would likely benefit from being taught explicitly in their composition classes how and when to use this modal appropriately in academic writing, and when this device is unnecessary or only appropriate for conversation. For example, L1 students used would to hedge when making a claim in their academic writing (e.g. "I would say..."), while this use of would is more common to conversation. Instructors of academic writing for ELL and L1 university students should do activities that bring this feature into students' awareness, and that train students to distinguish between the uses of would that are appropriate for 
academic writing and those that should only be used in conversation. The following sample activity helps students to notice, discuss and use would in academic text:

1. Students read a series of passages and determine whether each passage is from conversation or academic writing and explain their answer.

2. Students circle all tokens of would in each passage.

3. Students identify the time frame and speaker identity in each passage, and the purpose for using would in the context of the passage.

4. The instructor teaches students the various meanings of would.

5. Students match these meanings to the examples of would that they identified.

6. Students and teacher talk about which meanings of would are appropriate for use in academic writing, taking examples from the sample passages.

7. Students look at another handout of ungrammatical and uncommon uses of would, and collaborate on fixing each passage to follow the standards of academic writing.

This sample activity is illustrated by two student worksheets on the following pages (Figures 5.1 and 5.2). 
Figure 5.1: Sample materials: Contrasting uses of modal would in conversation and academic writing

\section{MODAL would ACTIVITY I:}

1. For each of the passages, determine whether it comes from conversation (C) or academic writing (AW). Write C or AW on the line and explain your answer.

Passage A:

Yeah, I mean, I talked to the restaurant waitress that would wait on them Saturday mornings, and she was a-gasp that we could have charged John Hamilton, because she would see them at breakfast together all lovey-dovey.

Register:

How do you know?

Passage B:

In January, the Defense Department met with scholars, who left the meeting convinced that their concerns had been heard and that the museums and ancient sites of Iraq would be protected.

Register:__ How do you know?

Passage C:

Look, I - I just want you protected. That's all I know. Please, would you ask Chris to come in? I really need to talk to him.

Register: __ How do you know?

Passage D:

For instance, a mechanic wearing a haptic glove could simulate reaching into a tight space and turning a screw. If the space were too narrowly designed for a human hand to perform the motion easily, the engineer would know to redesign that part of the line without ever having built a prototype.

Register: __ How do you know? 
Figure 5.1 (continued): Sample materials: Contrasting uses of modal would in conversation and academic writing

2. Circle would in each passage. Then fill out the chart for the time frame and speakers of each passage, and purpose that would has in each passage.

\begin{tabular}{|c|l|l|l|}
\hline Passage & $\begin{array}{l}\text { Time frame: tense and } \\
\text { aspect? Habitual or } \\
\text { completed action? }\end{array}$ & $\begin{array}{l}\text { Speakers: Pronouns }\left(1^{\text {st }},\right. \\
2^{\text {nd }}, 3^{\text {rd }} \text { person)? Clues } \\
\text { about identity? }\end{array}$ & $\begin{array}{l}\text { Purpose: Why does } \\
\text { the speaker/writer } \\
\text { use would? }\end{array}$ \\
\hline A & & & \\
\hline B & & & \\
\hline C & & & \\
\hline D & & & \\
\hline
\end{tabular}

3. Read each passage again. Then determine the register that uses each meaning, and the passage that contains an example of the meaning.

Meaning:

a. Hypothetical event or state

b. Future in the past tense

c. Habitual past action

d. Politeness/tentativeness
Register:

Passage:

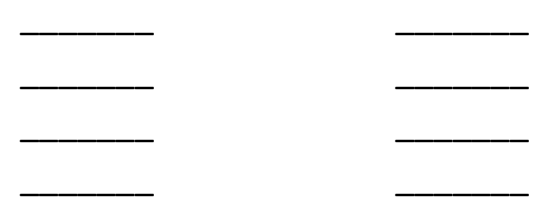

4. Complete the sentences:

a. In academic writing would is usually used to express and

b. In conversation, would is used to express the two meanings above, plus the other two meanings: and 
Figure 5.2: Sample materials: Correcting uncommon uses of would in academic writing MODAL would ACTIVITY II:

In the examples of academic writing below, circle each example of would. Then fill in the chart to answer the questions for each passage.

1. It was in 1843 that John Couch would move into the Oregon Territory and would be the one who was overseeing the building of the wharfs.

2. In closing, I would like to reiterate the argument that rights and morality are simply the result of behavioral evolution.

3. Portland has been notorious for numerous floods. As flooding would occur, they would need to clean up and clear out their storage underground.

\begin{tabular}{|l|l|l|l|}
\hline & Passage 1 & Passage 2 & Passage 3 \\
\hline $\begin{array}{l}\text { Which meaning of } \\
\text { would is used-- } \\
\text { future in the past, } \\
\text { habitual past, or } \\
\text { politeness? }\end{array}$ & & & \\
\hline $\begin{array}{l}\text { Is this use } \\
\text { common in } \\
\text { academic writing? } \\
\text { (refer to Activity I) }\end{array}$ & & & \\
\hline $\begin{array}{l}\text { Paraphrase the } \\
\text { passage without }\end{array}$ & & & \\
using would. & & & \\
\end{tabular}

4. Based on your answers above, how do you convey each purpose in academic writing?

\begin{tabular}{|l|l|l|}
\hline Purpose & Conversation & Academic writing \\
\hline $\begin{array}{l}\text { A past event that } \\
\text { has finished }\end{array}$ & simple past & \\
\hline Politeness & would like & \\
\hline Repeated past events & would + base form of verb & \\
\hline
\end{tabular}


Perfect aspect, passive voice, and reduced adjective clauses. L1 students seem to have already mastered these linguistic features, while ELL students are still in the process of acquiring these features in their academic writing. Because the ELL students have completed through level 4 of intensive English grammar courses, it is assumed that they have been taught about these features possibly a number of times. However, the instruction may not have included enough practice producing the various uses of each of these features in academic text.

In the case of reduced adjective clauses, ELL students may default to using a full adjective clause in post-nominal position instead of the reduced adjective clause; they have had more instruction and practice in how to form and when to use full adjective clauses, since these are introduced before the reduced adjective clauses in grammar books. What's more, reduced adjective clauses are very difficult for English language learners because sentences appear to have two main verbs. On the other hand, English L1 students at the university level have had more exposure than ELL students to how academic writing 'sounds', and while they might not have been taught about participle clauses, the use of this feature may be built into their native intuition about what 'sounds right'. Not only should teachers remind students that there is a choice between the full and reduced form, but also point out cases where an adjective clause should not be used at all.

Instructors of academic writing for ELL students should regularly engage students in practicing the use of perfect, passive, and reduced adjective clauses in their own writing. This begins with noticing usages of the features and being able to identify what 
makes these usages appropriate and effective. Also, students should practice noticing and correcting the absence of these features in cases where they are obligatory. Instructors can help students reinforce knowledge of these features and improve their ability to use them in writing through doing noticing activities similar to the one introduced for teaching modal would.

It-cleft. Of all the features found to be significantly different, the it-cleft construction was the least used by both groups of students. While the frequencies seem to suggest that L1 student have more experience with cleft constructions and understand how to form them and when to use them, it is likely that L1 students who are still obtaining their undergraduate education underuse this feature compared to writers at the professional level. Unlike the ELL students, who have received intensive English grammar instruction over many terms, the L1 students likely have not received explicit instruction about the form and function of cleft constructions. If the form and function of it-cleft were taught in freshman composition courses, students may end up utilizing this construction more often in their writing.

The it-cleft is an effective device for emphasizing contrast, which is especially useful for argumentation in academic writing. Instructors of both ELL and L1 students should encourage students to utilize this feature in their writing by teaching them its specific purpose and giving them opportunity to practice using it in an academic text. It may also be helpful to show students examples of $i t$-clefts in published writing and then have students practice adding this structure to sample sentences which lack the appropriate emphasis. However, instructors should caution students to not over-use this 
feature; to use it effectively, students have to be able to identify the appropriate context in which to use it.

Type/token ratio. Based on the observation that ELL students tend to over-rely on the repetition of key words to refer back to ideas in the text, it seems that ELL students do not know how to create cohesion in a text without repeating words. It seems that are not yet adept at how to utilize cohesive devices for this purpose. In addition, it is possible that students focus their attention on more significant issues such as grammar and content, so using a broader vocabulary to avoid repetition is an afterthought. Writing instructors should encourage students to develop their academic vocabulary, emphasizing that a wide range of vocabulary strengthens academic text by increasing the precision of their ideas.

\section{Limitations and Suggestions for Future Research}

There are several limitations to my study. First, I analyzed two small corpora of thirty papers each; with a larger corpus of student writing, patterns may have emerged that were not great enough to be significant in the corpora I compiled. Second, I analyzed thirteen linguistic features in each text, while some published studies have analyzed over sixty features (Hinkel, 2002; Biber, 1988). This means that there may be features that I chose not to test that actually do occur in significantly different frequencies between the two groups of essays. Third, while I did not differentiate ELL essays by the writer's L1, the comparison of ELL writing between L1 groups might have revealed particular disparities or needs for intervention that were not made evident by grouping all ELL 
essays together. While the scope of a master's thesis made the study of a more limited number of texts and features appropriate, future research should include a larger corpus of student writing, a wider selection of linguistic features, and a comparison of feature use by L1 group to lend deeper insight into ELL student writing.

In this study, the analysis of feature use in context was limited to the features that were found in significantly different frequencies. Even though the features associated with conversation were found in similar frequency rates between the two groups, further research could reveal how ELL and L1 essays use conversational features in their writing, and whether they use them for similar or different functions.

One limitation is also a strength of the study: All of the texts were written by students at one university. On one hand, this means that the findings are less likely to be applicable to students at other universities or in different levels of intensive English programs. On the other hand, this design is integral to the purpose of my study, in that the findings are intended to bring about a better understanding of the writing of a specific group of students, the international students studying in the IELP, and not the writing of students in a different intensive English program. In the future, graduate students or professional teachers at other universities could use this study as a model for carrying out research on student writing in their respective English language programs.

An additional area of future research is to delve deeper into the differences between ELL and L1 academic writing by performing a rhetorical analysis in addition to linguistic features analysis to determine if there is correlation between the frequency of 
each linguistic feature and the essay's score based on a teacher's observations. Another possible rhetorical analysis could be a quantitative study examining idea development, idea organization, integration of ideas to see if there a significant difference between the organizational features and discourse structure of the two groups.

In addition to a quantitative analysis, a related qualitative study would connect the frequency of linguistic features with teacher perceptions of what qualifies as "good" writing. Future researchers could interview professors in various disciplines about their expectations of student writing and ask them to identify examples of what they determine to be good student writing. The survey of professors and the linguistic analysis of student writing would be woven together to illuminate which features students should include in their writing. Another possible qualitative study would shed light on the students' perspective of what "good writing" is, the techniques they use to achieve good writing, what features they think are important in academic writing, and what messages they have received throughout their education about writing well.

Lastly, an analysis of formulaic language in the two groups of essays and in published academic writing would lend insight into the common collocations used by L1 students and professionals, but not by ELL students. This would inform writing instructors of the specific examples of formulaic language that would be helpful for ELL students to use in their own academic text. 


\section{Conclusion}

This study contributed to the field of English language teaching, specifically the instruction of academic writing for ELL students, in that it identified a gap between the writing of ELL students and the L1 students with whom they (will) take university courses. This gap points to recommendations for the features that writing instructors should reinforce in advanced ELL writing courses. Through continuing efforts to better understand our ELL students' writing capabilities and shortfalls, teachers of English for Academic Purposes can help their students reach their highest potential for success in U.S. universities. 


\section{References}

Aijmer, K. (2002). Modality in advanced Swedish learners' written interlanguage. In S. Granger, J. Hung, and S. Petch-Tyson (Eds.), Computer learner corpora, second language acquisition and foreign language teaching (pp. 55-76). Philadelphia: John Benjamins Publishing.

Albers, S. (2007). The Viking Corpus of Student Academic Writing (Unpublished master's project). Portland State University, Portland, OR.

Altenberg, B., \& Tapper, M. (1998). The use of adverbial connectors in advanced Swedish learners' written English. In S. Granger (Ed.), Learner English on computer (pp. 80-93). New York: Addison Wesley Longman Inc.

Barlow, M. (2004). MonoConc Pro 2.0. Houston, TX: Athelstan Publications.

Beck, J. H. (2007). The register of academic writing: A multidimensional comparison of German advanced EFL leaners and American native speakers (Unpublished master's thesis). Portland State University, Portland, OR.

Benesch, S. (1993). ESL, ideology, and the politics of pragmatism. TESOL Quarterly, 27, 705-717.

Benesch, S. (2001). Critical English for academic purposes. Mahwah, NJ: Lawrence Erlbaum Associates.

Biber, D. (1988). Variation across speech and writing. New York: Cambridge University Press.

Biber, D. (2006). University language. Philadelphia: John Benjamins Publishing.

Biber, D., \& Conrad, S. (2009). Register, genre, and style. New York: Cambridge University Press.

Biber, D., Conrad, S., \& Leech, G. (2002). Longman student grammar of spoken and written English. Essex: Pearson Education Limited.

Biber, D., Conrad, S., \& Reppen, R. (1998). Corpus linguistics: investigating language structure and use. New York: Cambridge University Press.

Biber, D., Johansson, S., Leech, G., Conrad, S., Finegan, E. (1999). Longman grammar of spoken and written English. Harlow, England: Longman.

Biber, D., \& Reppen, R. (1998). Comparing native and learner perspectives on English grammar: a study of complement clauses. In S. Granger (Ed.), Learner English on computer (pp. 145-159). New York: Addison Wesley Longman Inc. 
Bitchener, J., \& Knoch, U. (2010). Raising the linguistic accuracy level of advanced L2 writers with written corrective feedback. Journal of Second Language Writing, 19, 207-217. doi:10.1016/j.jslw.2010.10.002

Breyer, Y. A. (2011). Corpora in language teaching and learning. Frankfurt: Peter Lang.

Casanave, C. P. (2004). Controversies in second language writing. Ann Arbor: University of Michigan Press.

Chang, C-F., \& Kuo, C-H. (2011). A corpus-based approach to online materials development for writing research articles. English for Specific Purposes, 30, 222-234.

Chapelle, C. (1998). Some notes on systemic-functional linguistics. International Systemic Functional Linguistics Association. Retrieved from http://www.isfla.org/Systemics/documents/chapelle.html

Chen, Y-H. (2010). Lexical bundles in L1 and L2 academic writing. Language Learning \& Technology, 14, 30-49.

Chen, Y-S., \& Su, S-W. (2012). A genre-based approach to teaching EFL summary writing. ELT Journal: English Language Teachers Journal, 66, 184-192.

Cheng, F-W. (2008). Scaffolding language, scaffolding writing: a genre approach to teaching narrative writing. Asian EFL Journal, 10, 167-191.

Conrad, S. (1996). Investigating academic texts with corpus-based techniques: An example from biology. Linguistics and Education, 8, 299-326.

Crossley, S. A., \& McNamara, D. S. (2009). Computational assessment of lexical differences in L1 and L2 writing. Journal of Second Language Writing, 18, 119-135.

Crossley, S. A., \& McNamara, D. S. (2012). Predicting second language writing proficiency: The roles of cohesion and linguistic sophistication. Journal of Research in Reading, 35, 115-135. doi:10.1111/j.1467-9817.2010.01449.x

Davies, M. (2008-). The Corpus of Contemporary American English: 450 million words, 1990- present. Available online at http://corpus.byu.edu/coca/.

Diab, N. M. (2010). Effects of peer- versus self-editing on students' revision of language errors in revised drafts. System, 38, 85-95. doi:10.1016/j.system.2009.12.008

Evans, N. W., Hartshorn, K. J., \& Strong-Krause, D. (2011). The efficacy of dynamic written corrective feedback for university-matriculated ESL learners. System, 39, 229-239. doi:10.1016/j.system.2011.04.012 
Gardner, S. (2012). Genres and registers of student report writing: An SFL perspective on texts and practices. Journal of English for Academic Purposes, 11, 52-63.

Gillard, P., \& Gadsby, A. (1998). Using a learners' corpus in compiling ELT dictionaries. In S. Granger (Ed.), Learner English on computer (pp. 159-171). New York: Addison Wesley Longman Inc.

Gilquin, G., Granger, S., \& Paquot, M. (2007). Learner corpora: The missing link in EAP pedagogy. Journal of English for Academic Purposes, 6, 319-335.

Granger, S. (1998). The computer learner corpus: a versatile new source of data for SLA research. In S. Granger (Ed.), Learner English on computer (pp. 3-18). New York: Addison Wesley Longman Inc.

Granger, S. (2003). The International Corpus of Learner English: A new resource for foreign language learning and teaching and second language acquisition research. TESOL Quarterly, 37, 538-546.

Hinkel, E. (2001). Matters of cohesion in L2 academic texts. Applied Language Learning, 12, 111-132.

Hinkel, E. (2002). Second language writers' text: Linguistic and rhetorical features. Mahwah, NJ: Lawrence Erlbaum Associates, Inc.

Hinkel, E. (2003a). Simplicity without elegance: Features of sentences in L1 and L2 academic texts. TESOL Quarterly, 37, 275-301.

Hinkel, E. (2003b). Adverbial markers and tone in L1 and L2 students' writing. Journal of Pragmatics, 35, 1049-1068.

Hinkel, E. (2004). Tense, aspect and the passive voice in L1 and L2 academic texts. Language Teaching Research, 8, 5-29.

Hinkel, E. (2009). The effects of essay topics on modal verb uses in L1 and L2 academic writing. Journal of Pragmatics, 41, 667-683.

Hopkins, K. (2011, December 20). 10 U.S. colleges with highest ESL participation rates. U.S. News and World Report. Retrieved on April18, 2013 from http://www.usnews.com/

Hyland, K. (2000). Disciplinary discourses: social interactions in academic writing. New York: Longman.

Hyland, K., \& Milton, J. (1997). Qualification and certainty in L1 and L2 students' writing. Journal of Second Language Writing, 6, 183-205. 
Institute of International Education. (1955- 2011). Open doors: Fast facts international students in the U.S. Washingon, DC/ New York: Author.

Intensive English Language Program. (n.d.). Retrieved from http://www.ielp.pdx.edu/programs.php

IELP. (2013). Program Review Data. [Graphs and spreadsheets of student demographic and enrollment information]. Portland State University Intensive English Language Program, Portland, OR.

Jalilifar, A. (2010). Thematization in EFL students' composition writing and its relation to academic experience. RELC Journal, 41, 31-45. doi:10.1177/0033688210362621

Kathpalia, S. S., \& Carmel, H. L. H. (2011). Metaphorical competence in ESL student writing. RELC Journal, 42, 273-290. doi:10.1177/0033688211419379

Kongpetch, S. (2006). Using a genre-based approach to teach writing to Thai students: A case study. Prospect: An Australian Journal of Teaching/Teachers of English to Speakers of Other Languages (TESOL), 21, 3-33.

Kormos, J. (2011). Task complexity and linguistic and discourse features of narrative writing performance. Journal of Second Language Writing, 20, 148-161. doi:10.1016/j.jslw.2011.02.001

Laufer, B., \& Waldman, T. (2011). Verb-noun collocations in second language writing: a corpus analysis of learners' English. Language Learning, 61, 647-672.

Lorenz, G. (1998). Overstatement in advanced learners' writing: stylistic aspects of adjective intensification. In S. Granger (Ed.), Learner English on computer (pp. 53-66). New York: Addison Wesley Longman Inc.

Martin, J. R., \& Rose, D. (2008). Genre relations: mapping culture. London: Equinox.

Maseeh College of Engineering and Computer Science. (2011). Maseeh College of Engineering and Computer Science Arts \& Letters and Social Science Requirement. Retrieved from http://www.pdx.edu/sites/ www.pdx.edu.cecs/files/AL-SS_Approved\%205_20_2011.pdf

Negretti, R., \& Kuteeva, M. (2011). Fostering metacognitive genre awareness in L2 academic reading and writing: A case study of pre-service English teachers. Journal of Second Language Writing, 20, 95-110. doi:10.1016/j.jslw.2011.02.002

NEW University Writing Requirements. (n.d.). Retrieved from http://www.pdx.edu/advising/writing-requirement 
Nurmukhamedov, U., \& Kim, S. H. (2010). 'Would you perhaps consider...': Hedged comments in ESL writing. ELT J, 64, 272-282. doi:10.1093/elt/ccp063

Ong, J. (2014). How do planning time and task conditions affect metacognitive processes of L2 writers? Journal of Second Language Writing, 23, 17-30. doi:10.1016/j.jslw.2013.10.002

Ortega, L. (2003). Syntactic complexity measures and their relationship to L2 proficiency: A research synthesis of college-level L2 writing. Applied Linguistics, 24, 492-518. doi:10.1093/applin/24.4.492

Portland State University Facts. (n.d.). Retrieved from http://www.pdx.edu/portlandstate-university-facts

Profile. (n.d.). Retrieved from http://www.pdx.edu/profile/snapshot-portland-state

Quirk, R., Greenbaum, S., Leech, G., \& Svartvik, J. (1985). A comprehensive grammar of the English language. London: Longman.

Rafiei, K., \& Modirkhamene, S. (2012). Thematicity in published vs. unpublished Iranian TEFL theses. Theory \& Practice in Language Studies, 2, 1206-1213.

Ramanathan, V., \& Atkinson, D. (2011). Individualism, academic writing, and ESL writers. In P. K. Matsuda, M. Cox, J. Jordan, \& C. Ortmeier-Hooper (Eds.), Second language writing in the composition classroom (pp. 165-191). Boston: Bedford/ St. Martin's.

Reppen, R. (2012). Grammar and beyond level 1 student's book. New York: Cambridge University Press.

Santos, T. (1992). Ideology in composition: L1 and ESL. Journal of Second Language Writing, 1, 1-15.

Santos, T. (2001). The place of politics in second language writing. In T. J. Silva and P. K. Matsuda (Eds.), On second language writing (pp. 173-190). Mahwah, N.J.: L. Erlbaum Associates.

Shaw, P. (2009). Linking adverbials in student and professional writing in literary studies: What makes writing mature. In M. Charles, D. Pecorari, \& S. Hunston (Eds.), Academic writing: At the interface of corpus and discourse (pp. 215-235). New York: Continuum.

Simpson, R. C., Briggs, S. L., Ovens, J., \& Swales, J. M. (2002). The Michigan Corpus of Academic Spoken English. Ann Arbor, MI: The Regents of the University of Michigan. 
Siyanova, A., \& Schmitt, N. (2008). L2 learner production and processing of collocation: A multi-study perspective. The Canadian Modern Language Review, 64, 42958.

Smith, D. (2010.) IELP Grammar and Writing Curriculum. Updated by M. Mulder, 2012. Portland State University, Portland, OR

Smith-Barrow, D. (2013, December 24). 10 Colleges with the highest percentage of students in ESL. U.S. News and World Report. Retrieved on January 31, 2014 from www.usnews.com.

Swales, J. M. (1990). Genre analysis: English in academic and research settings. New York: Cambridge University Press.

Terzian, S. G., \& Osborne, L. A. (2006). Postwar era precedents and the ambivalent quest for international students at the University of Florida. Journal of Studies in International Education, 10, 286-306. doi: 10.1177/1028315306286919

University Studies Goals. (n.d.). Retrieved from http://www.pdx.edu/unst/university-studies-goals

UNST Introduction. (n.d.). Retrieved from http://www.pdx.edu/unst/unst-introduction

Wei, J. (2013). Corpus-based research on topical theme choices in Chinese and Swedish English learner writings. Theory \& Practice in Language Studies, 3, 2202-2208.

Yasuda, S. (2011). Genre-based tasks in foreign language writing: developing writers' genre awareness, linguistic knowledge, and writing competence. Journal of Second Language Writing, 20, 111-133. doi:10.1016/j.jslw.2011.03.001

Yayli, D. (2011). From genre awareness to cross-genre awareness: A study in an EFL context. Journal of English for Academic Purposes, 10, 121-129. doi:10.1016/j.jeap.2011.02.001 